\title{
INTFRFACF
}

Sociologias, Porto Alegre, ano 2, no 4, jul/dez 2000, p.306-353

\section{El impacto de la crisis fiscal en el trabajo en negro: las provincias de noroeste argentino.}

MARTA PANAIA

Miembro de la

Carrera de

Investigaciones

Científicas y

Técnicas del

CONICET

\section{Introducción}

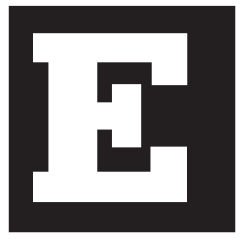

ste trabajo se enmarca dentro de los estudios sobre génesis, crecimiento y dinamismo del sector informal y aumento o disminución de la propensión a trabajar en condiciones de informalidad, ya sea por la forma de contrato (precariedad); por la forma de pago (evasión previsional o comúnmente llamado «en gris» o en negro) por su característica de clandestinidad (ilegalidad) o por realizarse en unidades económicas informales.

Hasta la década del '70 y durante todo el período sustitutivo de importaciones, la génesis y crecimiento de los sectores informales estaba alimentada por la migración campo/ciudad y la migración limítrofe y la puerta de entrada a los mercados de trabajo urbanos eran fundamentalmente la construcción y el servicio doméstico (Marshall, 1983; Beccaria y Orsatti, 1987 y 1990), ocupaciones tradicionalmente inestables.

A partir de mediados de la década del '80 en que comienzan a crecer fuertemente los trabajadores por cuenta propia y otras categorías informales, los estudios estuvieron centrados en los problemas de definición de los fenómenos: informalidad, subterráneidad, pobreza, falta de registro (Cf. INDEC, 1987 y Marshall, A., 1990; Beccaria, 1990, Rosental, 1990; 
Orsatti, 1990, Panaia, 1990; Lindenboim, 1990, Oiberman, 1990; Gallart, 1990; Monza, 1990; Feldman, 1990; Cortés, 1990 en Galín, P. Novick, M., 1990.); o en los problemas de medición, metodologías cuantitativas y cualitativas para cuantificar lo que no se registra, para estimar mediante proxis de medición, por métodos de contrastación, de saldos, por modelos matemáticos, modelos de aproximación fiscal, etc. (Cf. Frey y Weck, 1983a, 1983b y 1984; Tanzi, V. 1980. Beccaria, 1996; Orsatti, 1990; Minujin, 1993; Szretter, Panaia, 1991; Monza, 1985, 1995 y Monza y López, 1995) y, por supuesto, evaluaciones sobre el volumen de lo cuantificado, es decir, poder señalar cuántos de los trabajadores eran informales o qué proporción de la economía no estaba registrada o estaba funcionando» en negro».

En la década del '90, lo que aumenta a valores desconocidos para la economía argentina son los desocupados y los estudios tienden a centrarse en la relación crecimiento/ empleo; en el estudio de los mercados de trabajo; en el nivel de desocupación; en la duración del tiempo de desempleo; y en las posibilidades futuras de empleabilidad de estos sectores (Cf. Beccaria, 1995; Monza y López, 1995, Cortés, 1990; Feldman, 1990 y Murmis y Feldman, 1996; Salvia, 1993, y Salvia, 1997; CEPEL, №2, 1998).

Sigue habiendo pocos estudios que expliquen la articulación macro/mesoeconómica de la evasión previsional y fiscal sobre el mercado de trabajo (Cf. Tanzi, 1980 y Frey y Weck, 1983a y 1983b; y 1984; Barbeito, A. y Lo Vuolo, R., 1993; Cetrángolo, O. y Machinea, J.L., 1992; Cetrángolo y Jimenez, 1998; Rofman, R., 1998) y muy pocos, por lo tanto, que traten de instrumentar o evaluar los efectos de la génesis de este fenómeno en la aplicación de políticas.

En general, los métodos de evaluación fiscal se basan en aproximaciones realizadas a partir de los volúmenes recaudados y los porcentajes retenidos. Sobre esta base se diseñan políticas con los perfiles del contribuyente y del evasor, sin tomar en cuenta otros datos del contexto (Gómez Sabaini y Santiere, 1993).

Nuestro enfoque también significa un enfoque territorial diferente a la visión regional tradicional. En nuestra óptica se complementa la 
organización territorial del mercado de trabajo con la incidencia de las políticas tributarias y fiscales y al mismo tiempo con un tratamiento por 'clusters' que permite asociar las provincias conformando regiones no solo por sumatoria o continuidad territorial, sino en base a las existencias de infraestructura que produce una similitud de los niveles regionales de demanda y de gestión política frente a los comportamientos económicos. ${ }^{1}$

Usualmente, la estadística trabaja con datos nacionales y es posible que esto todavía tenga una cierta utilidad, pero lo que se llama actualmente economía ha estallado fuera de los límites de lo que hoy llamamos nación, de la misma manera que lo que llamamos poder económico efectivo se ha trasladado tanto hacia arriba al nivel global, como hacia abajo hacia el nivel regional de la ciudad global (Cf. Sassen, Saskia, 1991, 1994).

\section{El trabajo sin aportes previsionales}

Entonces, este es un trabajo en progreso, que tiene todavía muchas hipótesis en constatación. Una de ellas es la que nos ocupa en este trabajo, sobre la génesis del trabajo en negro que explica su crecimiento como contracara de la evasión impositiva, en los períodos de crisis para amortiguar la dureza de los ajustes económicos, con posteriores y variados procesos de blanqueo (Cf. Saba, A. 1981 y Charmes, J., 1992).

Esta evasión sería la fuente de financiamiento de las actividades informales y del aumento de la rentabilidad de las empresas, particularmente a partir de la disminución de los costos de trabajo, pero también de la competencia desleal, la subfacturación/sobrefacturación, las transacciones ficticias, el fraude, etc. Como mostraremos más adelante las propias características del sistema tributario argentino y, fundamentalmente, el sistema

\footnotetext{
1 Cf. Scott, 1996. En un documento reciente este autor defiende la tesis de que el capitalismo mundial se está moviendo hacia una fase de desarrollo marcada por una regionalización intensificada por la producción, cubierta por y arraigada en una división global del trabajo. En este proceso, señala, está ocurriendo una relocalización significativa de las funciones económicas de coordinación y dirección, independientemente del Estado Soberano, entre los niveles internacional por arriba y regional, por abajo.
} 
de distribución interjurisdiccional de los ingresos tributarios, favorece la evasión por su conflictividad, inequidad e ineficiencia.

La inestabilidad de interjuego de estos determinantes, hace que las mediciones puntuales sean rápidamente obsoletas y que las configuraciones macroeconómicas que se dan en un momento, difícilmente se mantengan por períodos de largo aliento. ${ }^{2}$

Con este criterio ninguna política de empleo podría dejar de estar acompañada de una política fiscal y previsional, pero al mismo tiempo, ninguna instrumentación de políticas puede desconocer las configuraciones conyunturales, que pueden requerir diferencias significativas con la política de largo plazo. Es decir, debe combinar la flexibilidad del corto y mediano plazo con la estabilidad de objetivos de largo plazo. ${ }^{3}$

La falta de mercados de largo plazo, afecta en países como la Argentina el tipo de decisiones que adoptan las firmas para asegurar su supervivencia en el mercado, aumentando la falta de coordinación micro/macro.

Mirada desde las actividades no registradas por las Cuentas Nacionales, los sectores que más han tendido a crecer y que por lo tanto requerirían de la discusión de su inclusión fiscal son:

1. Las economías domésticas, que han buscado por mecanismos de mercado paliar los niveles de subsistencia y las fuertes desigualdades en la distribución del ingreso de los hogares.

2. Las economías asociativas, que por su bajo perfil en la economía competitiva sirvieron de mecanismo idóneo para realizar fuertes transacciones y recibir importantes donaciones sin pagar impuestos internos, por ser legalmente exentos. Particularmente Asociaciones, Fundaciones, Clubes Deportivos, Sindicatos, Partidos

\footnotetext{
2 Entiendo por «configuración» la articulación momentánea de factores macroeconómicos determinantes del mercado de trabajo: oferta/demanda; política fiscal/política de inversiones; etc; que no obstante ser importantes no tienen continuidad en el tiempo como para mantener efectos permanentes en el proceso económico de conjunto, pero pesan fuertemente en las conyunturas o el corto plazo. Un análisis amplio de los efectos macroeconómicos de este tipo de proceso se puede encontrar en Du Tertre, C. 1996.

3 Una visión más profunda de la complejidad de la relación micro/macro en la economía argentina puede verse en Katz, Jorge, 1996.
} 
Políticos, Iglesias, etc.

3. Los espacios no regulados de la economía que han tenido un rápido crecimiento por cambios tecnológicos u otro tipo de innovaciones en el procedimiento de producción. En estos espacios falta una adecuada regulación de retención impositiva, lo cual por ahora permite grandes ganancias.(Por ejemplo fotocopiado de material bibliográfico, piratería de programas informáticos, publicidad, copiado de material audiovisual, etc.)

4. Las economías ilegales o clandestinas en parte acrecentadas por los bajos controles a la corrupción administrativa y financiera ${ }^{4}$, en parte, impulsada por la internacionalización del tráfico de drogas, armas, órganos y otros productos exóticos.

Mirada desde la estructura impositiva, la evasión se podría analizar en varios niveles:

1. La evasión previsional, es decir, la falta de pago de los impuestos del trabajo, que asciende actualmente a 1700 millones de pesos mensuales, aproximadamente.

2. La distribución de los aportes fiscales, particularmente los impuestos coparticipados.

3. Otros impuestos como Ganancias, IVA, Ingresos Brutos y demás impuestos internos.

Mirado desde los mercados de trabajo, es necesario analizar:

1. El efecto sobre el crecimiento o la propensión del trabajo en negro o sin pago de aportes, a partir de la reducción de los impuestos al trabajo.

2. El efecto sobre el crecimiento o la propensión del trabajo en negro a partir de la mayor evasión y la crisis fiscal.

\footnotetext{
4. Cada vez se hace más evidente el impacto en cifras millonarias que tiene la corrupción administrativa en la economía del país, lo mismo que la pesada carga de una administración ineficiente. Sin embargo, hay pocas cuantificaciones sistemáticas y lo que es peor, pocos intentos sistemáticos de convertir la administración en un aparato meritocrático y eficiente. Cf. Conesa, E. 1996.
} 
3. El efecto sobre el crecimiento o la propensión del trabajo en negro a raíz de la crisis productiva y la apertura de los mercados, las políticas de promoción industrial o la conformación del MERCOSUR.

Por último, mirado desde lo regional, sería importante poder definir:

1. El comportamiento diferenciado por región, respecto del total del país

2. La definición de las crisis regionales como productivas o como fiscales

Dentro de este panorama más amplio, este trabajo se focaliza sobre los efectos de la crisis fiscal en el aumento a la propensión del trabajo en negro, en la zona patagónica. Pero daremos sucintamente una visión del efecto a nivel general del país, para poder comprender mejor el fenómeno regional.

Por último, queremos señalar que la base de datos de este trabajo se procesa con una metodología econométrica, que tiene serias limitaciones, pero que consideramos que nos permite construir un proxi bastante adecuado a nivel de las provincias y suficientemente abarcativo como para captar un proceso inobservable, que a través de los restantes métodos ya que han mostrado que presentan sesgos importantes ${ }^{5}$.

Es por esta razón, que si bien la base del trabajo se logra con un procedimiento econométrico para poder correlacionar 17 variables, luego se contrastan estos datos así obtenidos con otras fuentes provenientes de estudios de casos cualitativos y análisis en profundidad para contrarrestar algunas de las limitaciones de estos instrumentos (Cf. Salvia, A. y Panaia, M., 1997; Axelrad, 1998).

\footnotetext{
5 La econometría provee una muy tenue corroboración de las teorías económicas; sin embargo, tampoco hay test que permita abandonar las teorías económicas que hagan uso de la econometría. Para Popper, la econometría es la ciencia social por excelencia con lo cual se agudiza el problema de la refutabilidad de las teorías económicas: Popper supone que es la precisión de la econometría la que debe ser puesta a prueba, puesto que es ella la que provee la mejor base empírica de una teoría económica posible.

No obstante estos supuestos de Popper no han sido confirmados y muy por el contrario fueron puestos en duda porque ciertas dificultades con la econometría han mostrado que es un instrumento incierto y no confiable; entre otros motivos porque: 1) utiliza siempre un conjunto incompleto de factores relevantes; 2) siempre hay omisión tendenciosa de ciertas variables; 3 ) construye modelos con variables inobservables, como expectativas; 4) infiere falsamente causas de nuevas correlaciones; 5) confunde relevancia económica con mera relavancia estadística y, por último, opera con tamaños inadecuados de muestras; 6) debe trabajar con datos secundarios relevados con otros fines. Consecuencia de todo esto, es que la econometría proporciona pocas posibilidades para refutar las teorías económicas. Popper, 1967.
} 


\section{Los determinantes del mercado de trabajo sin aportes}

Consideramos que los determinantes del trabajo sin pago de aportes previsionales o trabajo pagado «en negro» son de cuatro órdenes:

1. La estructura impositiva previsional y del mercado de capitales que utiliza el sistema productivo;

2. El comportamiento social frente a la evasión, el cumplimiento de los pagos previsionales, las políticas de moratoria y la corrupción;

3. El nivel de empleo/desempleo que aumenta o disminuye los incentivos para trabajar en la economía subterránea;

4. El grado general de desarrollo de la economía y el nivel de ingresos per cápita que condiciona estrategias como el pluriempleo, la doble ocupación, la evasión de los cotizantes autónomos y la disminución general de los aportes fiscales.

No desarrollaremos en este trabajo estos cuatro puntos, nos concentraremos en profundizar el primero, si bien en realidad los otros tres están implícitos en las múltiples variables utilizadas en este método como causa y como efecto, de manera que si bien no las consideramos en especial en este trabajo, están definiendo los resultados obtenidos en nuestro mapa.

El estado del debate actual sobre el tema muestra una fuerte inestabilidad del peso de los determinantes más importantes y nuestra construcción del mapa 1980/1985 (Cf. Panaia, M, 1991) nos permite inferir cómo se relacionan estos determinantes entre sí. No obstante, se observan todavía muchas variaciones en el período 1991/1994, a pesar de que se ha logrado una mayor estabilidad de la economía.

Sintéticamente, los resultados que hemos obtenido de la construcción de dos mapas de Economía Subterránea uno en base a los datos de 1980/85 (Cf. Panaia, M., 1991) y el otro en base a los datos de 1991/1994 muestran que hay una mayor propensión general al trabajo con evasión previsional, legalizada y alentada 
desde las propias políticas de empleo en todo el país.

La espacialización nos permitió visualizar mejor las zonas donde se aplicaron determinado tipo de políticas de otras zonas donde predominó otro tipo de dispositivos y produjo distintos comportamientos regionales.

La finalidad de construir un mapa fue agrupar las provincias de acuerdo al mayor peso de los determinantes observables, para analizar su propensión al crecimiento del mercado de trabajo»en negro».

La base de la comparación fue la construcción de una matriz de distancias donde las provincias, caracterizadas por los valores obtenidos en la correlación de 17 variables por un coeficiente de Speerman, se clasificaron en grupos por sus «parecidos».

La superposición de varios mapas en el tiempo nos permitió analizar efectos de políticas sobre el empleo regional de una manera sencilla y no solo tomar en cuenta las tendencias sino también los efectos de políticas con baterías diferentes.

Este modelo es el LISREL (Lineal Interdependent Structural Relationship) que es la generalización del MIMIC (Multiple Indicators, Multiple Causes). ${ }^{6}$

El modelo consta de dos partes, un modelo de medición y un modelo de ecuaciones estructurales. El primero parte de indicadores observables para medir indicadores inobservables.

El segundo especifica las relaciones de causalidad acerca de las variables inobservables, mediante una regresión múltiple. ${ }^{?}$

En nuestro trabajo dada la imposibilidad de construir variables numéricas de suficiente grado de complejidad, como las requeridas por el modelo, hemos reemplazado la regresión por un análisis por cluster, que cumple la misma función con variables más rudimentarias (Ver Anexo).

El tema que nos ocupa tiene una dimensión de difícil medición, porque no puede ser observada directamente que es el tamaño de la economía subterránea

6 Este método fue explicitado por Jöreskog and Golderberger (1975) y Jöreskog and Van Thillo (1973).

7 Un método alternativo puede encontrarse en Lamarche,C. y Porto, G., 1997, para medir el efecto empleo en la relación infraestructura, coparticipación federal, empleo público y desempleo, que está bastante cerca del estudio que nosotros proponemos, pero como va adicionando las variables de a una y las hace co variar de a dos, no puede captar las variables inobservables. De esta forma solo puede explicar las variables con alta asociación negativa o positiva y no capta las «configuraciones» de variables que mencionábamos más arriba. Cf. Panaia, M, 1991 y Panaia, M. 1998. 
y la especial configuración de variables que intensifica la propensión o la disminuye, pero esa dimensión está incidida por una serie de determinantes que son exógenos y observables y que logran medirse con menor error con la construcción de indicadores complejos, que a través de indicadores simples.

Por otra parte, el modelo de medición teórico adquiere consistencia estableciendo hipótesis acerca de los factores más determinantes del tamaño de la Economía Subterránea, en cada momento de medición y de los indicadores más significativos de estos determinantes.

En nuestro caso, se agrupan las provincias (casos) teniendo en cuenta valores correspondientes a 17 variables que se construyeron teniendo en cut los contenidos teóricos expuestos, manteniendo la confrontación entre «der da» (infraestructura, servicios, empresas, etc) y «oferta» (cantidad de personas c padas; de manera de detectar las incongruencias respecto de la capacidad instal y la declaración de mano de obra en el sector (Cf. Barthelemy, 1987; Saba, 19 Schiray, 1983/1).

Teniendo en cuenta las características del problema se decidió trabajar un método de clusters no jerárquicos. Entre estos métodos se escogió el del centrc paraochodusters ${ }^{8}$.Toda la zona fronteriza tiene un incremento de 4 puntos prome de aumento a la propensión, pero especialmente en la región NOA y NEA.

Además, en casi ninguna región se da una superposición de la región そ gráfica y productiva con la región estadísticamente construida, en cambio hay superposición casi perfecta en la zona patagónica. Es por esa razón, que focalizamos nuestro primer trabajo fundamentalmente en la zona patagónica.

El mapa realizado para el período 1980/85 (Cf. Panaia, M., 1991; op. cit.) había marcado la zona patagónica con una propensión muy débil al trabajo «en negro». Entre sus provincias se encontraba la más «blanca» del país - Neuquén -, que justificó un estudio especial para analizar la evolución y las causas de su baja propensión (Cf. Axelrad, S., 1998). En esta segunda etapa, en cambio afrontaremos

\footnotetext{
8 Según este método, se eligen los ocho casos más alejados a los que se denomina centroides iniciales, que constituyen el punto de partida de los ocho clusters que se van a formar, luego se agrupa el resto de las observaciones con el centroide más próximo; una vez concluida esta primera etapa, se re calculan los centroides de cada uno de los agrupamientos y se vuelve a reconsiderar la pertenecia de cada caso a un grupo. El procedimiento continúa hasta que la variancia dentro de los grupos sea la mínima posible.
} 
el análisis de una de las zonas con mayor propensión al trabajo en negro del país. 4. El sistema regional del NOA

\section{Mapa de trabajo sin aportes jubilatorios $1980-1985$}

INSTITUTO NAOIONAL

DE ESTADISTICAS Y GENSOS

REPUBLIOA ARGENTINA

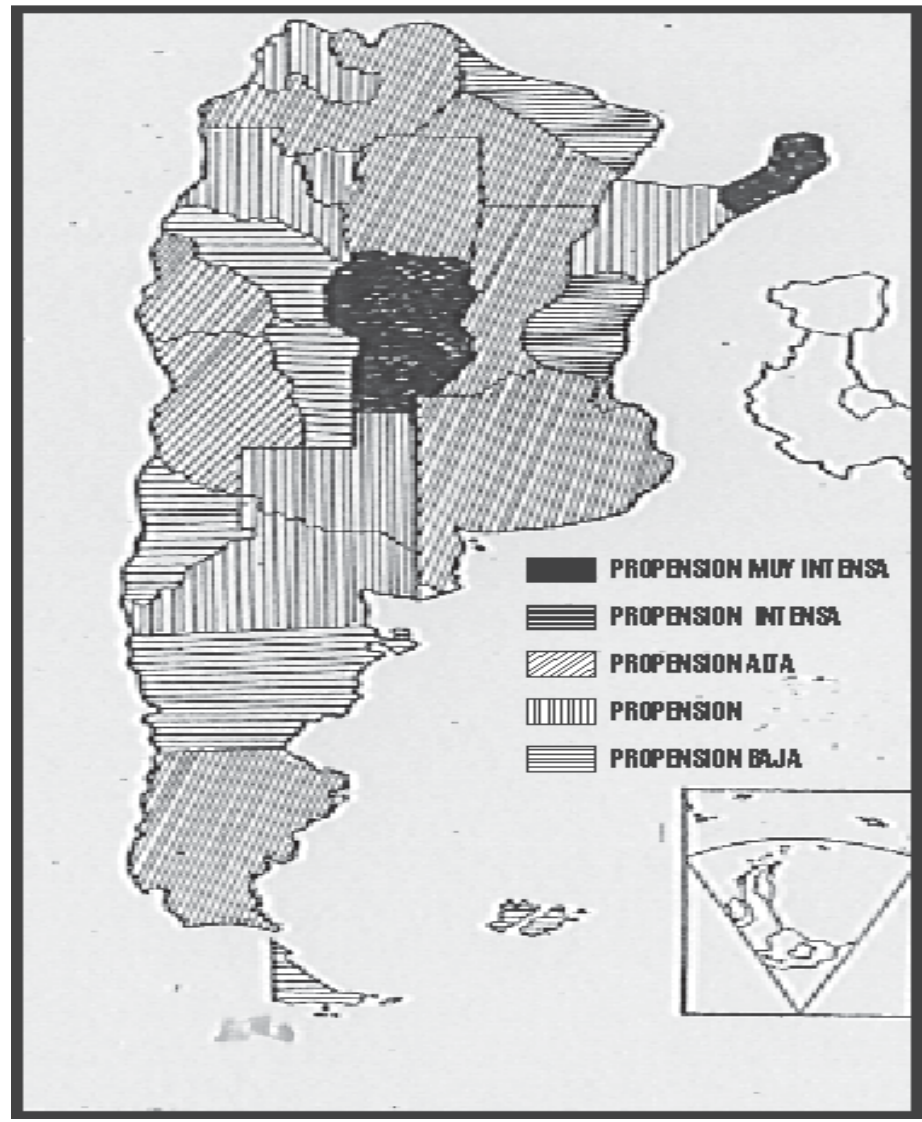


Mapa de trabajo sin aportes jubilatorios 1991-1995

INSTITUTO NACOM DE ESTADISTICAS Y CENSOS REPUBLICA ARGENTINA
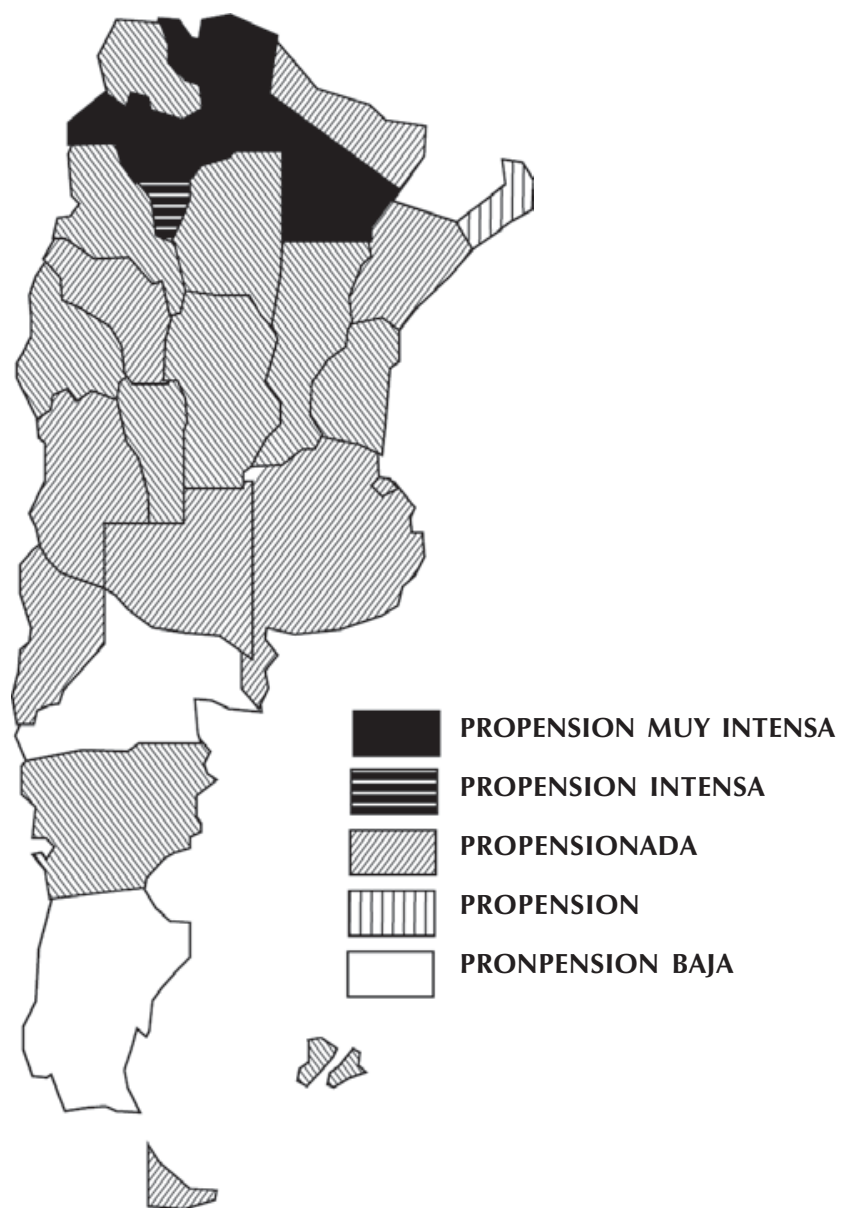
En este segundo estudio tomamos la región del NOA, donde las provincias mostraban los índices más altos de propensión al trabajo en negro en los dos mapas mencionados y donde el crecimiento entre los dos períodos era en promedio mayor.

Paradójicamente, las provincias que tienen los puntajes extremos de propensión al trabajo en negro quedan fuera de la región tal como nostros la trabajamos, si bien son dos provincias fronterizas del norte Misiones y Formosa.

Analizar los mercados de trabajo regionales nos lleva a algunas consideraciones previas. El noroeste argentino ha sido una zona marginal y marginada, una región aislada del país con importantes desinversiones públicas, con sobrecostos de fletes y otras condiciones adversas que dificultaron históricamente la viabilidad de los grupos productores de éstas provincias. De allí

que los niveles de funcionamiento de la economía de los que se parte no son ni siquiera pre-competitivos respecto de la región pampeana.

Uno de los procesos que pone en evidencia esta década de funcionamiento de la convertibilidad es que muchas de las crisis productivas dependen de la estructura, la organización y el funcionamiento propio de cada empresa. Pero también pesa negativamente la falta de rutas, los costos más altos de los fletes y peajes y la falta de inversiones en infraestructura, es decir

la inestabilidad de la demanda.

Por otra parte, los estudios realizados sobre la región ayudan a tener una visión compleja de la misma y llaman la atención sobre los principales puntos del debate sobre los mercados de trabajo regionales ${ }^{9}$.

Los aportes más recientes ${ }^{10}$ muestran que el trabajo asalariado crece el 22\% entre 1969 y 1988 según los Censos Agropecuarios y logra una importante concentración en el mercado de trabajo del NOA. También es 
esta región la crece en establecimientos minifundistas. Según señala Neiman , esta tendencia hacia el crecimiento del trabajo asalariado concomitante con el aumento de los trabajadores con tierra genera una situación de polarización social y de segmentación ocupacional al mismo tiempo que se manifiesta entre otras en esta zona y que va en detrimento de los sectores medios.

Algunos autores hablan de pluriactividad, otros de multiocupación ${ }^{11}$ y en los trabajos de campo realizados ésta a veces aparece como trabajo de otra fuente agrícola o de fuentes extragrícolas. Me parece interesante destacar que el NOA concentra casi el $17 \%$ del empleo agropecuario permanente, casi el $18 \%$ de los productores agropecuarios del país y casi el 15\% de los trabajadores asalariados, según el Censo Nacional de Población. de 1991. Los productores asalaridos del NOA, según los datos analizados por Neiman en el Censo Nacional Agropecuario de 1988, alcanzaba ya casi el 29\%.

Lamentablemente no se ha realizado el Censo nacional Agropecuario en 1999 y los datos históricos tienen ciertas limitaciones para analizar el proceso de borramiento de los límites entre el mercado de trabajo urbano y rural ya que los datos más adecuados para este tipo de análisis no son abarcativos de todo el mercado sino solo del área urbana o de la rural y, además, con los conglomerados del interior para los cuales existen datos no es posible hacer análisis regionales que respeten mínimamente las regiones existentes en el país, menos aún captar los procesos de subocupación y desocupación al interior de las provincias; el proceso de urbanización de los trabajadores rurales y el juego de lo local y el impacto de la globalización.

EI NOA es fundamentalmente rural y no industrial, pero a pesar de ello tiene una importante población urbana. El promedio de población urbana de la región es de casi el $76 \%$

y el $24 \%$ es rural, pero hay provincias como Santiago del Estero en que la población rural alcanza casi el 38\% y encambio en Salta no llega al 20\%.

Las características productivas de la actividad agropecuaria del NOA

11 Giarracca, N.1994. 
Sociologias, Porto Alegre, ano 2, no 4, jul/dez 2000, p.306-351

\begin{tabular}{|c|c|c|c|c|c|c|c|c|c|}
\hline \multicolumn{10}{|c|}{ Cuadro №1 } \\
\hline \multicolumn{10}{|c|}{$\begin{array}{c}\text { Evolución de los recursos fiscales de origen nacional } \\
\text { (en millones de pesos) }\end{array}$} \\
\hline \multirow{6}{*}{ 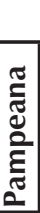 } & \multirow{6}{*}{$\begin{array}{l}\text { Buenos Aires } \\
\text { Córdoba } \\
\text { Entre Ríos } \\
\text { La Pampa } \\
\text { Santa Fe }\end{array}$} & \multicolumn{2}{|c|}{1993} & \multicolumn{2}{|c|}{1994} & \multicolumn{2}{|c|}{1995} & \multicolumn{2}{|c|}{1996} \\
\hline & & 3109,2 & 51,5 & 3347,4 & 52,2 & 3282,6 & 52,7 & 3500,8 & 52,0 \\
\hline & & 1024,5 & 17,0 & 1084,1 & 16,9 & 995,6 & 16,0 & 1124,5 & 16,7 \\
\hline & & 596,4 & 9,9 & 624,5 & 9,7 & 603,0 & 9,7 & 651,8 & 9,7 \\
\hline & & 249,4 & 4,1 & 258,3 & 4,0 & 248,9 & 4,0 & 270,1 & 4,0 \\
\hline & & 1052,1 & 17,4 & 1100,7 & 17,2 & 1094,1 & 17,6 & 1188,6 & 17,6 \\
\hline & Subtotal I & 6031,6 & 100,0 & 6415,0 & 100,0 & 6224,2 & 100,0 & 6735,8 & 100,0 \\
\hline \multirow{6}{*}{$\begin{array}{l}\overleftarrow{T} \\
\mathbf{Z} \\
\end{array}$} & Catamarca & 331,8 & 16,0 & 344,5 & 16,0 & 330,0 & 13,0 & 351,6 & 12,9 \\
\hline & Jujuy & 360,3 & 17,4 & 374,9 & 17,4 & 363,8 & 14,4 & 392,4 & 14,4 \\
\hline & La Rioja & 265,3 & 12,8 & 273,2 & 12,7 & 270,1 & 10,7 & 286,8 & 10,5 \\
\hline & Salta & 479,3 & 23,1 & 498,2 & 23,2 & 482,4 & 19,1 & 516,6 & 19,0 \\
\hline & Stgo.Del Estero & 497,9 & 24,0 & 515,4 & 24,0 & 494,0 & 19,5 & 536,0 & 19,7 \\
\hline & Tucumán & 139,4 & 6,7 & 143,8 & 6,7 & 590,1 & 23,3 & 638,7 & 23,5 \\
\hline \multicolumn{2}{|r|}{ Subtotal II } & 2074,0 & 100,0 & 2150,0 & 100,0 & 2530,4 & 100,0 & 2722,1 & 100,0 \\
\hline \multirow{4}{*}{ 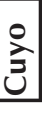 } & Mendoza & 532,5 & 42,8 & 555,7 & 43,2 & 536,5 & 43,0 & 573,9 & 42,7 \\
\hline & San Juan & 410,3 & 33,0 & 426,8 & 33,2 & 414,3 & 33,2 & 445,1 & 33,1 \\
\hline & San Luis & 301,1 & 24,2 & 304,4 & 23,7 & 295,7 & 23,7 & 325,9 & 24,2 \\
\hline & Subtotal III & 1243,9 & 100,0 & 1286,9 & 100,0 & 1246,5 & 100,0 & 1344,9 & 100,0 \\
\hline \multirow{5}{*}{ 出 } & Corrientes & 452,9 & 24,4 & 480,2 & 24,6 & 465,1 & 24,6 & 508,3 & 24,8 \\
\hline & Chaco & 555,4 & 29,9 & 583,7 & 29,9 & 564,7 & 29,9 & 613,4 & 29,9 \\
\hline & Formosa & 424,8 & 22,9 & 442,7 & 22,7 & 430,2 & 22,8 & 467,3 & 22,8 \\
\hline & Misiones & 421,9 & 22,7 & 444,1 & 22,8 & 429,2 & 22,7 & 464,2 & 22,6 \\
\hline & Subtotal IV & 1855,0 & 100,0 & 1950,7 & 100,0 & 1889,2 & 100,0 & 2053,2 & 100,0 \\
\hline \multirow{7}{*}{ 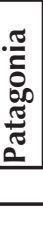 } & Chubut & 251,2 & 15,2 & 256,2 & 15,0 & 245,9 & 20,6 & 267,7 & 20,5 \\
\hline & Neuquén & 255,5 & 15,5 & 266,5 & 15,6 & 253,4 & 21,3 & 280,8 & 21,5 \\
\hline & Río Negro & 328,4 & 19,9 & 342,2 & 20,0 & 328,1 & 27,5 & 358,2 & 27,4 \\
\hline & Santa Cruz & 227,6 & 13,8 & 236,8 & 13,9 & 227,1 & 19,0 & 248,5 & 19,0 \\
\hline & Tierra del Fuego & 586,2 & 35,6 & 607,7 & 35,6 & 137,7 & 11,6 & 150,0 & 11,5 \\
\hline & Subtotal V & 1648,9 & 100,0 & 1709,4 & 100,0 & 1192,2 & 100,0 & 1305,2 & 100,0 \\
\hline & Total del país & 1285 & 3,4 & 1351 & 1,8 & 1308 & 2,3 & 141 & 61,0 \\
\hline
\end{tabular}

Fuente: FIDE en base a datos del Ministerio de Economía.En millones de pesos.

con fuerte presencia del monocultivo, en sectores como el azúcar, el algodón y el tabaco y el aislamiento en materia de infraestructura que aumenta los costos del flete no ayuda a su desarrollo productivo.

La crisis productiva de los monocultivos ha pernmitido la expansión 
del sector citrícola, pero la gran cantidad de establecimientos agropecuarios de pequeño y mediano tamaño dificulta la economía en escala, el logro de precios más competitivos y el acceso a bajos costos de los insumos necesarios.

A pesar de las políticas dirigidas a mejorar la rentabilidad de las empresas agropecuarias, la región del NOA es la que muestra menor acceso ${ }^{12}$ posiblemente por el temor de los productores a endeudarse. Estos programas encarados durante el gobierno menemista cubrieron el $25 \%$ del total de los grupos de la zona o sea aproximadamente 4500 productores y también representó el 25\% de los fondos asignados para el total del país ${ }^{13}$. En Salta y Jujuy, por otra parte, hubo mayor resistencia en ingresar a estos programas, por la importancia de la actividad tabacalera y la escasa presencia del INTA de la zona en estos Programas.

Hay que destacar que el Fondo Especial del Tabaco que supera los 100 millones de pesos, desde 1994 se restituyó a las provincias productoras y está dedicado al financiamiento y la reconversión del sector tabacalero.

Argentina es un país dual en muchos sentidos, dos velocidades de desarrollo, dos grandes áreas, la pampeana moderna y fértil y la extrapampeana más tradicional y árida.

En la década del 70 se da una redistribución del PBG del país que se caracteriza por una disminución del área pampeana y un incremento de las restantes áreas, particularmente la Patagonia que es la que más crece (5,3\%). La que más crece de las áreas extrapampeanas es el NOA que presenta una tasa anual acumulativa del 2,9\%.

Si analizamos el comportamiento provincial al interior del NOA veremos que Santiago del Estero es la provincia que más decrece 3,6\% y es también la que presenta valores más bajos de incremento de la producción.

Catamarca, en cambio, duplica su participación a pesar de ser todavía

\footnotetext{
12 Durante la última década funcionaron Programas como el de Cambio Rural y el Programa Social Agropecuario basados en la asistencia técnica y la vinculación al crédito para las PyMes agropecuarias para encaminarlas a un proceso de reconversión.

13 La distribución de los fondos tenía que ver con el número de pymes de la región y no con el PBI generado por el sector para que la distribución fuera más equitativa respecto de la región pampeana que históricamente concentró los mayores recursos.
} 
la de valores más bajos dentro del contexto. Tucumán sigue siendo la provincia de mayor aporte si bien no

alcanza al 40\% logrado en la década del 80 y Salta mantiene con altibajos, los valores históricos del 24\%. La Rioja tiene cambios significativos, pero en las regionalizaciones recientes se plantea la discusión sobre su pertenencia al NOA sur o su integración a la región cuyana norte.

Si se analiza la estructura sectorial de la región desde el punto de vista del producto, el sector más importante es el de servicios, particularmente por el peso del sector público, el sector industrial en Tucumán que tiene los valores más altos no alcanza al 30\%, Santiago del Estero tiene el 7\% y el promedio regional sin La Rioja es de 19,7\%.

El Acta de reparación histórica de 1974, que establece privilegios de desgravación impositiva para las cuatro provincias históricamente postergadas (Catamarca; La Rioja y San Luis) tuvo importantes efectos positivos para las provincias involucradas, pero fue muy controvertida por las provincias pobres que quedaron excluídas como Santiago del Estero. Además mantiene vivos conflictos de larga data entre provincias.La provincia de Salta compite históricamente con Catamarca y La Rioja por la radicación de la industria textil algodonera y vitivinícola. Es diferente, en cambio, para el proceso de producción del olivo y la jojoba.

Es innegable que esta Acta Acuerdo produce importantes distorsiones en el sistema de precios relativos y en la decisiones de localización industrial que toman las empresas ${ }^{14}$.

Según señala Katz , las características del sistema industrial argentino se basa en plantas pequeñas que tienen mayores costos de operación y menos capacidad de competir, producto de una historia centrada en la sustitución de importaciones y la comercialización para el mercado interno.

A éstos se agrega, según Katz, diferentes mix de producción ${ }^{15}$ muy

14 Las leyes de promoción industrial no siempre tienen especificaciones de región que coincidan con las regiones tal como las conocemos hoy.Así el Decreto 9477/61 promueve el NOA, por ejemplo, pero entiende por NOA San Juan, Catamarca, La Rioja, Santiago del Estero, Tucumán, Salta,Jujuy, Chaco, Formosa, Santa Fé Norte y Córdoba norte. la zona B del Decreto 3113/64 coincide aproximadamente con la región NOA del decreto 6130/61. 
variados que multiplica las deseconomías de escala. Estos factores combinados generan una deficitaria organización de la producción que incrementa los costos financieros, de mantenimiento de los stocks intermedios y finales. Esta situación produjo desbalances históricos en el crecimiento industrial de las distintas regiones y muchas de ellas han perdido en términos relativos al crecimiento industrial del país.

Este desequilibrio tenía una contrapartida institucional hasta 1994, ya que de hecho toda la asistencia técnica para la región del NOA estaba centrada en la Capital Federal hasta esa fecha. En 1994, también se regionaliza el INTI en 8 regiones y la sede del NOA pasa a la ciudad de Tucumán ${ }^{16}$.

Poblacionalmente, el NOA mantiene su participación relativa con un leve crecimiento del 2,0\% entre 1970 y 1991, pero los análisis al interior de la región muestran que Salta es la provincia que más crece, casi un $2 \%$ y Santiago del Estero la que más decrece, casi un $4 \%$.El mercado de trabajo del NOA se caracteriza por las bajas tasas de participación laboral registradas en sus provincias y esto se debe a que las fuertes restricciones ocupacionales que desalientan la oferta hacia la inactividad o el trabajo sin aportes, característico en provincias como Jujuy y Santiago del Estero.

Por otra parte, en el noroeste las consecuencias del modelo de ajuste adoptado en 1991, las privatizaciones, los concesionamientos y las crisis productivas de las economías provinciales produjeron un fuerte aumento del desempleo abierto y de la subocupación horaria, particularmente en algunas categorías de empleo como el servicio doméstico.

A la cada vez más intensa incorporación de empresas de explotación de minerales se suma que la privatización de YPF ha generado una desocupación especialmente crítica en la zona de Gral Mosconi, la independización del Ferrocarril Gral Belgrano, ${ }^{17}$ y la privatización de Gas

15 Composición de la relación equipo/mano de obra.

16 En 1992 se aprueba el Regimen de Especialización Industrial y en 1993 se crea el Centro de Información y Estadísticas Industriales, que tienen 32 filiales en todo el país. 
del Estado, que es gente que tiene ya una formación profesional en el área gasífera y petrolera. También ha generado despidos e indemnizaciones y un incipiente ajuste de planta en los estados provinciales que marca un crecimiento persistente de sus empleados desde 1983.

La producción minera argentina es mínima, representa el 0,3\% del PBI y la cantidad de minas productivas registradas ronda las 12500, mientras que el empleo generado por el sector alcanza apenas a 16000 personas a nivel nacional.

En 1974 se sanciona la Ley de Promoción Minera 20751 que se modifica en 1979 con la ley 22.095. En 1989 con la instalación de la emergencia económica esta ley que se hallaba en vigencia se utiliza para el otorgamiento de subsidios y la desgravación de impuestos que en los últimos 15 años de aplicación le significó el Estado un sacrificio de 440 millones de dólares de ingresos fiscales.

Así se sancionan en 1992 las leyes de Inversiones Mineras, de Reordenamiento Minero y el Acuerdo Federal. La primera, prevé la estabilidad fiscal para todas las inversiones mineras por 30 años. Esto tiende a favorecer la radicación de empresas mineras.

También tienen un tratamiento impositivo diferencial todas las inversiones en prospección, exploración y obras de infraestructura. Las empresas pueden deducir hasta el $200 \%$ del impuesto a las ganancias, exime automáticamente del impuesto a los activos, se permite la incorporación de equipos y maquinarias al país sin pagar ningún derecho, lo que convierte a nuestro país en un puerto franco para incorporar tecnología para la minería. Se establece un techo de no más del $3 \%$ a las regalías que cobran las provincias ${ }^{18}$. También se prevé la capitalización de las reservas y la constitución

17 En 1993, al fracasar el intento de privatización por concesión del Ferrocarril Gral Belgrano, se decide escindirlo de Ferrocarriles Argentinos y crear una sociedad anónima independiente, ya que su situación era insostenible en esas condiciones. El Ferrocarril Gral Belgrano pasa de 4,8 a 1,2 millones de toneladas de carga ; de 250 a 43 locomotoras en funcionamiento; de transportar 50.000 a 2000 personas; de 22345 a 1484 empleados de planta entre 1990 y la actualidad.

CF. Ludueña, Ignacio; 1994.

18 Solo 4 de las 23 provincias argentinas cobran regalías. 
de un fondo del $5 \%$ para mitigar el impacto ambiental de la actividad.

La segunda ley de Reordenamiento Minero obliga a inventariar y mapear los recursos mineros en un plazo de 3 años $^{19}$ y declara como zona 1 de interés al NOA. Esta normativa también modifica el Código de Minería que ya tenía 105 años de antiguedad y preveía cánones muy bajos para la actividad. Se institucionaliza el Consejo Federal de Minería para que las provincias dueñas de los yacimientos puedan participar como asesores de la Secretaría de Minería. Por último, se firma el Acuerdo Federal para desarrollar la minería y para ello se prevé un reintegro anticipado del IVA a los 60 días para la compra de bienes de capital.

Durante la década del 90, se incrementa en más de 60 las empresas dedicadas a la explotación minera. Algunos casos involucran grandes empresas internacionales ya que las empresas nacionales no se encuentran en condiciones de emprendimientos de esta naturaleza. Por ejemplo, la empresa americana FMCLithium Co, va a explotar sales de litio en la Puna argentina, en la zona del Salar del Hombre Muerto.

En la Provincia de La Rioja está ubicado el Nevado de Famatina donde la empresa FDA (Australia) tiene un proyecto para explotar un yacimiento diseminado de cobre, molideno y oro. El proyecto más importante de Catamarca es el de Bajo La Alumbrera de explotación de cobre diseminado y pórfido de cobre con una importante reserva.

El centro de operaciones es la ciudad de Andalgalá, pero requiere una importante inversión en infraestructura, entre ellas una línea de alta tensión hasta Tucumán y 1100 km de vías férreas hasta el puerto de Rosario. Participan de este proyecto Australia, Canadá, empresas de Catamarca y la Universidad de Tucumán. La inversión mayor es en la construcción de infraestructura, que en un futuro puede generar más de 2000 puestos de trabajo en el sector y 3600 puestos indirectos en servicios en la zona, si se cumple lo proyectado.

El Plan de construcciones nacionales y provinciales genera en este 
período alrededor de 30.000 puestos de trabajo, en el NOA, que no alcanzan a dinamizar el mercado de trabajo del sector, seriamente presionado por el creciente aumento de innigrantes ilegales que se distribuyen en la zona.

Sin embargo, se puede considerar todavía insuficiente la infraestructura de la región para constituir una demanda estable y varias obras importantes están en plena realización, tienen problemas de financiamiento o de aprovechamiento, como el Canal del Tunal, Cabra Corral, Peñas Blancas, etc. Algo similar ocurre en la Cuenca del Bermejo.

Este esquema se repite en el transporte y en la terminación de rutas de conexión o integradoras con la Puna y con Chile, que cumplen un papel fundamental en la disminución de los costos del transporte de los productos y la creación de vínculos terrestres en el Mercosur ${ }^{20}$.

Allí cabe mencionar la lentitud de la construcción del corredor bioceánico del Norte que conecta Uruguayana con Corrientes y luego con Santiago del Estero y con Salta, la ruta 34 al norte de Metán, que incluye Bordo/Metán; Bordo/Olleros y desde Olleros al Quebrachal. Está planificada para pavimentar desde Pozo Hondo hasta Rosario de la Frontera, pero no se han iniciado las obras. Y por último desde Humahuaca hasta La Quiaca para poder llegar a Bolivia por la ruta 9 y el acceso a la ciudad de Salta por Guemes. También la ruta 51 desde Campo Quijano hasta San Antonio de los Cobres, que tiene marcadas pendientes muy peligrosas para el paso de camiones; la ruta 16 y la ruta 70 que están a cargo del gobierno de Jujuy.

La reestructuración de la red vial de toda la región del NOA cambia de sistema de financiamiento, pasando de las tradicionales licitaciones al sistema $\mathrm{COT}^{21}$, que le permite al Estado convertirse en un administrador de contratos, diseños,

\footnotetext{
20 Dentro del Plan de inversiones del período se encuentra interrumpida una importante inversión en infraestructura en rutas para combinar el transporte fluvial y el terrestre con salida por el Puerto de Barranqueras y la negociación con Chile por la apertura de dos pasos Jama y Sico para asegurar la llegada de los productos al Pacífico. En 1994, Chile licita unilaterlmente los estudios sobre el paso de Jama desde San Pedro de Atacama.Cf. Otrera, 1994.

21 COT significa Construir/Operar/y Transferir. Consiste en licitaciones por tramos y por un período de 10/12 años donde las empresas ofrecen cobrar una cuota mensual por realizar el trabajo por ese período. Gana la empresa que ofrece la cuota más conveniente. El sistema se instala en el año 1993 y previamente se hizo un llamado de preclasificación de empresas para ver las condiciones que proponen y cuántas se encuentran en condiciones de hacerlo.Se presentaron a esa preclasificación 56 empresas.
} 
ejecuciones y supervisiones de obra, reduciendo de esta manera las contrataciones de personal de 15.000/16000 a 3600/3500 empleados.

Estos planes de inversiones deben ir acompañados de planes de reestructuración tarifaria de los servicios y de reestructuración fiscal para asegurar el abaratamiento del costo del trasporte por carretera y del comercio internacional ${ }^{22}$.

La situación estructural, muestra una situación diferencial del crecimiento económico, del empleo y la propensión a trabajar en negro y de las desigualdades sociales en la región.

El sector informal urbano tiene dimensiones considerables en Tucumán y Jujuy donde atrae la población rural más afectada por problemas de empleo. La década del 90 suma al aumento creciente del desempleo abierto, el mantenimiento de valores muy altos del subempleo horario. Las posibilidades de superar esta situación son muy pocas si se toma en cuenta el sobreempleo estatal de estas provincias y el retraso de la reestructuración de los Estados provinciales que todavía amortiguan los efectos de la convertibilidad y un ajuste fiscal que todavía no se ha puesto en marcha.

Esta situación de empleo urbano se ve acrecentado por los problemas de sector rural donde persisten explotaciones de bajo rendimiento y sectores que utilizan nuevas tecnologías ahorradoras de mano de obra expulsando fuerza de trabajo.

A los problemas de generación o expulsión de empleo de los productos tradicionales de la zona, como el tabaco y el azúcar, se suman los de los no tradicionales como los cítricos y las bananas.

A grandes rasgos la población urbana con problemas de empleo se acerca al 35\% y en la población rural al 51\%. En el área urbana estos problemas están vinculados con la desocupación abierta y el trabajo sin aportes, en tanto que en el ámbito rural se destacan sobre todo las dificultades

22 La Ley 17520 de Concesiones para el mantenimiento por el sistema de peaje establece los incrementos y las ganancias de las empresas en el sistema.En todos los casos de concesiones por el sistema de peaje se tiene en cuenta que la tarifa que paga el usuario debe ser inferior al beneficio del mismo.También se toma en cuenta la razonabilidad de la rentabilidad de la empresa. 
referidas a la subocupación.

En ambos sectores, tanto el rural como el urbano predomina el subempleo en las mujeres de 25 a 65 años y en los jóvenes de ambos sexos que son los que realizan, en general, tareas sin remuneración fija de ayuda familiar.

Estos segmentos, tanto el de las mujeres como el de los jóvenes tienden cada vez más trabajar en forma autónoma. De las políticas instrumentadas desde el gobierno durante el período, para la región fueron dedicadas al NOA alrededor del 14\% del monto total de las mismas.

La proporción de beneficiarios que se localizan en el NOA es similar al porcentaje de desocupados que tiene la región, que es aproximadamente del $14 \%$ de los desocupados de todo el país, pero no significó una solución estructural, sino soluciones conyunturales y provisorias, porque las inversiones programadas para generar demandas estables de empleo como las obras de infraestructura y las inversiones productivas quedaron fuertemente retrasadas y el endeudamiento fiscal y previsional aumentó en la década.

Para poder comprender mejor la relación entre las variables impositivas y sus efectos en el mercado de trabajo, tal vez sea conveniente avanzar primero en comprender algunos rasgos generales del sistema tributario argentino, que aguarda todavía una reforma estructural.

Básicamente, sería importante tener en cuenta el aumento del déficit fiscal nacional, los desequilibrios propios del sistema tributario que se apoya más en la tributación general al consumo y al trabajo de los sectores de menores ingresos y, por último, el desbalance fiscal vertical o inequidad en los repartos provinciales y municipales que ven disminuidos los aportes nacionales y carecen de recursos propios para asumir la responsabilidad fiscal de sus propias provincias y municipalidades.

Hasta 1994 hubo superávit fiscal, a partir de allí el déficit fiscal aumenta, por el incremento de los gastos de gobierno, la reforma previsional y el aumento de la presión impositiva. Esto coincide con la disminución de los aportes patronales, que fue diferencial por provincias.

5. La estructura impositiva previsional y del mercado de 


\section{capitales que utiliza el sistema productivo}

El aumento de la evasión y las reestructuraciones tributarias que se han realizado durante el período han tenido importantes repercusiones en el mercado de trabajo.

Existen pocas estadísticas confiables sobre la distribución de la renta nacional ya sea por tramos de ingresos, fuentes generadoras de renta, por sectores de actividad económica u otros. Sí se puede establecer una suma aproximada que representa el 20\% del PBI Nacional y que ascendía a 14600 millones de dólares en 1992.

Cuál es el efecto de este volumen de impuestos en el sistema productivo y en la distribución del ingreso, no es fácil de precisar. En principio hay que ver cómo se repartió a lo largo de la historia la presión tributaria de las distintas áreas recaudadoras. Administración Nacional (DGl, Aduana, etc.) Sistema de Seguridad Social y la proveniente de los sistemas provinciales y la MCBA.

Durante los años 1993/1994 hay un aumento sensible de la recaudación que fue producto de una mayor transferencia del sistema tributario acompañados por la reducción o eliminación de los regímenes de promoción, la generalización de la base imponible del IVA a algunas actividades productivas exentas y a los servicios. Sin embargo, ese impulso no se mantiene por diferentes razones, entre las cuales se puede mencionar los efectos de la crisis mexicana, la recesión económica, la falta de presión política en el cobro de los impuestos, la lentitud de las reformas tributarias más estructurales que requería el sistema y el agotamiento de las políticas de corto plazo (Cf. Gómez Sabaini, J. C. y Gaggero, J., 1997. op. cit.).

A partir del Plan de Convertibilidad, los efectos más significativos fueron el aumento en la recaudación tributaria, las modificaciones en el IVA y las medidas tendientes a la realización del Pacto Fiscal Federal, que a la fecha de la presentación de este artículo estaba todavía en debate, y la Reforma al Sistema Previsiona ${ }^{23}$. 
Las contribuciones y aportes al Sistema de Seguridad Social tienen un peso significativo hasta la Reforma de 1994, luego tienden a bajar. Estos tributos inciden en su totalidad sobre el ingreso de los asalariados y en muchos casos, el componente del aporte patronal para jubilaciones se traslada a los precios de los bienes de consumo.

La clasificación por tipos de impuestos tienen dos grandes divisiones, los directos que teóricamente, no son trasladables por la vía de los precios de los bienes o de los factores a otros agentes económicos. Los indirectos, que son los que en principio tienden a trasladarse a los precios de los bienes transados o de los factores de la producción.

Dentro de los directos está el impuesto a la renta que tiene un alto porcentaje que proviene del pago de personas físicas que trabajan dentro de la 4ta categoría, que se encuentran fuera de los tramos más elevados de la distribución del ingreso y el volumen de lo recaudado varía según el monto de los mínimos no imponibles.

En nuestro país, se puede decir que este impuesto no tiene un criterio distribucionista sobre los distintos niveles de ingreso y tampoco se respeta la equidad horizontal, ya que el grado de evasión y de cumplimiento de las distintas fuentes de renta varía siempre.

\footnotetext{
23 En 1998, el Senado aprueba el proyecto del legislador cordobés José Manual de la Sota (Partido Justicialista). El proyecto original establecía que el déficit fiscal total del sector público no podía superar el $1 \%$ del PBI, lo cual restringía los gastos de la Administración Central. En el recinto se eliminó este ítem y se sustituyó por una distinción entre gastos corrientes (sueldos, subsidios, etc) que se estableció en 1,5\% del PBI para el año 2000 y del $1 \%$ para el año 2001 y de gastos de capital, que se amplió a 2\% del PBI.

Esta norma legislativa propone, además, la creación de un Fondo de Estabilización Fiscal para ser utilizado en caso de crisis internacional o interna. Este Fondo contará con el $2 \%$ de los recursos del Tesoro y el 30\% del producto de la venta de activos públicos y puede alcanzar hasta el $50 \%$ de la suma del déficit fiscal y la amortización de deudas del ejercicio fiscal de la administración nacional.

También se prevén sanciones para los funcionarios públicos que transgredan las normas y la disolución de los organismos descentralizados cuyo financiamiento por parte del Tesoro sea igual o superior al $90 \%$ del total de sus gastos corrientes y de capital con exclusión de las Universidades Nacionales y el Consejo Nacional de Investigaciones Científicas y Técnicas (CONICET).

Se encuentra todavía en debate cierta debilidad expresada en que los límites impuestos al gasto dependen del crecimiento del PBI, con lo cual su verdadero control puede ser una quimera; y una debilidad tal vez más grave expresada en metas de endeudamiento que pueden crecer al mismo ritmo que el déficit ,más la capitalización de intereses, más los créditos que la Nación consiga para las provincias y lo dispuesto en las leyes de consolidación de deuda. Por último el Fondo de Estabilización Fiscal es bastante limitado ya que lo integra solo el 2\% de los Recursos del Tesoro Nacional sumados a un porcentaje de los ingresos de capital y sin el aporte de las Provincias. (Cf. debates de la Nación y El Clarín del 23 de mayo y días siguientes de 1999)
} 


\begin{tabular}{|c|c|c|c|c|c|c|c|c|c|}
\hline \multicolumn{10}{|c|}{ Cuadro №2 } \\
\hline \multicolumn{10}{|c|}{$\begin{array}{c}\text { Recursos corrientes/NOA } \\
\text { Coparticipación Federal 1985/1993 } \\
\text { (En millones de pesos) }\end{array}$} \\
\hline Jurisdicción & 1985 & 1986 & 1987 & 1988 & 1989 & 1990 & 1991 & 1992 & 1993 \\
\hline Tucumán & 258 & 283 & 268 & 229 & 231 & 223 & 321 & 462 & 470 \\
\hline Salta & 206 & 220 & 216 & 185 & 186 & 179 & 259 & 369 & 376 \\
\hline Santiago del Estero & 222 & 241 & 233 & 199 & 201 & 193 & 281 & 390 & 394 \\
\hline Jujuy & 153 & 168 & 160 & 137 & 138 & 133 & 192 & 276 & 280 \\
\hline Catamarca & 143 & 159 & 155 & 133 & 134 & 129 & 186 & 258 & 261 \\
\hline La Rioja & 112 & 118 & 117 & 100 & 101 & 97 & 140 & 198 & 202 \\
\hline Total NOA & 1094 & 1189 & 1149 & 983 & 991 & 954 & 1379 & 1953 & 1983 \\
\hline Total NOA (\%) & 22,01 & 21,33 & 21,12 & 20,41 & 20,40 & 20,34 & 20,30 & 19,70 & 19,65 \\
\hline Total País & 4970 & 5575 & 5440 & 4817 & 4857 & 4691 & 6794 & 9913 & 10093 \\
\hline
\end{tabular}

Nota: 1983/1990 actualizado s/índice de precios combinados promedio 1991 y a partir de esa fecha a precios corrientes.

Fuente: Base de datos de la Secretaría de Asistencia para la Reforma Económica Provincial Tomo II. Diciembre de 1995.

Otro tipo de problemas proviene de las exenciones existentes, en los períodos inflacionarios, de los efectos no distributivos de la inflación y, por último, de los altos niveles de inflación, especialmente en el período previo a la convertibilidad.

En cuanto a los impuestos patrimoniales, un tercio corresponde a personas físicas, que es lo que importa en cuanto a sus efectos distributivos y oscila en el 0,6\% del PBI. Después de las reformas de 1985, los contribuyentes llegaron a 200.000, con lo cual el tributo, prácticamente se duplicó, pero los altos índices inflacionarios de los años posteriores y los cambios legislativos, minaron ese aumento.

En la última década en términos del $\mathrm{PBI}$, los impuestos patrimoniales bajan de 1,6 a 1,2 puntos lo que en términos porcentuales representa una caída del 9\% al $7 \%$.

La reforma de mayor envergadura se produce en 1989 con la reducción de la alícuota para sociedades de capital constituidas en el país, que siempre había sido del $33 \%$ y pasa a ser del 20\% y luego en 1992 se vuelve a elevar al 30\%. En cuanto a la base imponible, la mayor reforma proviene de la inclusión de las fuentes de 
ingreso extranjeras

Otras reformas fueron las modificaciones al régimen de quebrantos impositivos acumulados por las empresas y los pagos a cuenta de los aportes personales a la Seguridad Social (Cf. Gómez Sabaini, J.C. y Gaggero, J., 1997, op. cit).

Durante todo el período resultan sustanciales las modificaciones de los impuestos que gravan al trabajo, tanto asalariado como autónomo y tanto referido a las alícuotas correspondientes como a las bases imponibles.

Tal vez el más importante de estos cambios es el que se produce en la reforma del sistema previsional que se inicia en Julio de 1994. La Reforma consiste básicamente en la coexistencia del régimen mixto de reparto con carácter estatal y de capitalización con aportes, de carácter privado.

Las modificaciones en las contribuciones patronales se aprobaron en 1991, agregándose el 5\% proveniente del FONAVI y se desglosó el 9\% correspondiente a las asignaciones familiares en un 7,5\% para asignaciones y un 1,5\% para el Fondo Nacional de Empleo. Esto no modificó en sí mismo los montos globales, pero sí la distribución de la imposición.

En 1992, se introducen las modalidades promovidas destinadas a estimular el empleo que incluyeron la reducción de las contribuciones patronales (Cf. Feldman, S., 1995).

No obstante, la medida de mayor impacto en la recaudación impositiva fue la rebaja de las contribuciones patronales establecidas como consecuencia del Pacto Fiscal Federal. Estas rebajas comenzaron a operar en 1994 y luego de algunos problemas producidos por la crisis mexicana fue profundizada a fines de 1995 y principios de 1996.

Según cifras oficiales, la reducción promedio en las contribuciones patronales, a partir del primer trimestre de 1996 fueron del 31\%, mientras que para el mismo período de 1995 había sido del 15\%. Esto significó en términos de recursos perdidos 4500 millones de pesos equivalentes a 2 puntos del PBI.

Sin embargo, esta pérdida no se tradujo en un aumento del empleo como consecuencia de las desgravaciones, aunque sí se produjeron fuertes efectos favorables e indiscriminados sobre los márgenes empresarios. 
Otro cambio introducido por la Reforma Previsional fue la elevación de la tasa de aportes personales de 10 a 11\% y la fijación de un piso y un techo a la base imponible (Cf. Gómez Sabaini, J.C. y Gaggero, J., 1997, op. cit. y Durán, V., 1996).

Los impuestos indirectos son considerados regresivos, porque son pagados en una mayor proporción por quienes tienen ingresos menores. Son básicamente el IVA, los impuestos internos (bebidas y cigarrillos) y los impuestos a los combustibles. El primero produce entre el 5 y el $6 \%$ de la recaudación de los impuestos internos y el de las naftas, representa una parte muy pequeña de la recaudación.

La recaudación de impuestos por la venta de cigarrillos pasó de representar el del 70\% de los impuestos internos al 62\%, que rige actualmente desde 1991, a partir de un acuerdo con los empresarios del sector en que se mantendrían los montos de recaudación, lo cual quiere decir que se alentó un aumento del consumo con el consecuente daño que esto significa para la salud.

El sistema de imposición a los combustibles sufrió también reformas a raíz de la desregulación del sector petrolero. En principio, el gravamen fue establecido de acuerdo a una base específica según el tipo de combustible y se autorizó al Poder Ejecutivo a modificar los valores unitarios del impuesto.

En 1992, se implementó la desgravación de combustibles, con excepción de las naftas y en 1993, se llevó a cabo con el gas natural.

En cuanto al IVA se si considera una sola tasa y sin exenciones, para todos los bienes de consumo, su efecto sobre el consumo será proporcional, pero su efecto sobre el ingreso será regresivo y más regresivo aún sino estuvieran gravados bienes cuyo acceso está limitado a los sectores de mayores ingresos.

En la Argentina, el IVA ha sufrido fuertes cambios en su orientación, por esa razón resulta difícil apreciar sus efectos de tipo distributivo. De 1975 a 1979, el tributo tenía una base imponible restringida, entre 1980 y 1983, tiene una base amplia, pero con tasas diferenciales y de 1983 a 1989, con muchas exenciones y a partir de 1990 con una gran cobertura, alcanzando inclusive a los servicios y con tasa única.

En síntesis, los impuestos trasladables al consumidor final de bienes y servicios representan aproximadamente el $70 \%$ del total de la recaudación, mientras que 


\begin{tabular}{|c|c|c|c|}
\hline \multicolumn{4}{|c|}{ Cuadro №3 } \\
\hline \multicolumn{4}{|c|}{$\begin{array}{c}\text { Recursos Tributarios y Gastos Totales de las Provincias } \\
\text { Noroeste argentino y Total del País - } 1995 \\
\text { (en millones de pesos) }\end{array}$} \\
\hline & & & Recursos Tributários \\
\hline Jurisdicciones & Recursos Tributários & Gastos totales & Gastos totales \\
\hline Catamarca & \begin{tabular}{|c|}
22 \\
\end{tabular} & 433 & 0,05 \\
\hline La Rioja & 42 & 702 & 0,06 \\
\hline Jujuy & 16 & 590 & 0,03 \\
\hline Salta & 99 & 821 & 0,12 \\
\hline Santiago del Estero & 53 & 626 & 0,08 \\
\hline Tucumán & 132 & 1004 & 0,13 \\
\hline Total NOA & 364 & 4176 & 0,09 \\
\hline Resto del País & 8452 & 25167 & 0,33 \\
\hline Total País & 8816 & 29343 & 0,30 \\
\hline
\end{tabular}

Fuente: Elaboración propia en base a datos de la Subsecretaría de Asistencia a las ProvinciasMinisterio del Interior.

\begin{tabular}{|c|c|c|c|c|c|c|c|c|c|}
\hline \multicolumn{10}{|c|}{ Cuadro №4 } \\
\hline \multicolumn{10}{|c|}{$\begin{array}{l}\text { Distribución de los recursos corrientes del NOA } \\
\text { Coparticipación Federal 1985/1993 } \\
\text { (En \%) }\end{array}$} \\
\hline Jurisdicción & 1985 & 1986 & 1987 & 1988 & 1989 & 1990 & 1991 & 1992 & 1993 \\
\hline Tucumán & 23,58 & 23,80 & 23,32 & 23,30 & 23,31 & 23,38 & 23,28 & 23,66 & 23,70 \\
\hline Salta & 18,83 & 18,50 & 18,80 & 18,82 & 18,77 & 18,76 & 18,78 & 18,89 & 18,96 \\
\hline Santiago del Estero & 20,29 & 20,27 & 20,28 & 20,24 & 20,28 & 20,23 & 20,38 & 19,97 & 19,87 \\
\hline Jujuy & 13,99 & 14,13 & 13,92 & 13,94 & 13,93 & 13,94 & 13,92 & 14,13 & 14,12 \\
\hline Catamarca & 13,07 & 13,37 & 13,50 & 13,53 & 13,52 & 13,52 & 13,49 & 13,21 & 13,16 \\
\hline La Rioja & 10,24 & 9,93 & 10,18 & 10,17 & 10,19 & 10,17 & 10,15 & 10,14 & 10,19 \\
\hline Total NOA & & & & & & & & & \\
\hline
\end{tabular}

Fuente: Elaboración propia en base a datos de la Secretaría de Asistencia para la Reforma Económica Provincial. Tomo II. Diciembre de 1995.

solo el 30\% que proviene de la imposición directa permite ejercer la función distributiva en forma tradicional.

Existen pocos estudios sobre la presión tributaria por niveles de ingreso y también por tamaño de empresa, que serían fundamentales para tener datos obje- 
tivos sobre la propensión al trabajo «en negro». Uno de ellos (Cf. Santierre, 1989) muestra que para los estratos más bajos la presión tributaria es mayor y alcanza el 20 a 21\%, en los estratos medios baja, y sube, pero muy poco,en los estratos altos.

Cuando la presión tributaria se mira sobre los ingresos familiares, se puede ver que el más pesado es el de los pagos previsionales 3,3\%; luego el del valor agregado 2,8\% y, por último, el del impuesto a los combustibles 2,4\%. En los pagos previsionales, tomando los deciles de ingreso, se puede observar una leve caída de la presión en el último decil, como consecuencia del menor contenido de los salarios observable en las familias de ingresos altos.

En resumen, la política tributaria puede moderar las desigualdades en la distribución del ingreso, pero no incide en la estructura ${ }^{24}$.

\section{La lógica regional de la distribución de los recursos}

La lógica de la distribución de recursos se relaciona con la asimetría interjurisdiccional existente entre responsabilidad de gastos y disponibilidad de recursos. Como algunos autores señalan (Cf. Cetrángolo, O. y Jimenez, 1998; Gómez Sabaini, J. C. y Gaggero, J., 1997; Durán, V. y Sabaini, J. C., 1995), suele prevalecer un mayor grado de concentración de la recaudación tributaria en manos del nivel central y, por lo tanto, los gobiernos provinciales y municipales, dependen financieramente del gobierno central, dando origen a diferentes sistemas de transferencias intergubernamentales.

Mientras el gobierno nacional tiene una parte cada vez menor de los gastos, obtiene una parte mayoritaria de los recursos tributarios que recauda, que se asignan a cada provincia por medio de un complicado régimen de coparticipación ${ }^{25}$.

En el caso de las provincias, es evidente que a partir de 1991 se producen importantes transformaciones y que los recursos propios que se

\footnotetext{
24 Otro enfoque posible es el del gasto social para lo cual se puede Cf. Dieguez, Llach y Petrecolla, 1990. 25 A pesar de las diferencias de metodologías y de fuentes que hacen que los distintos autores no coincidan en las estadísticas, a título indicativo señalaremos que entre 1993 y 1995, los gastos del gobierno nacional en relación del PBI solo se incrementan en 1\% del PBI. El valor de 17,4\% sobre el PBI del año 1995 reitera el nivel de erogaciones de 1998 y 1991 . En este período el gasto se concentra en prestaciones de seguridad social, cancelación de deuda pública y transferencia a provincias.
} 
utilizan para financiar gastos entre 1993 y 1995 son similares a los recursos utilizados en 1986.

Hay ciertas similitudes entre los altibajos de financiamientos del gasto tributario que aparecen reflejados en el mapa 1980/85 y los que surgen del análisis de los datos del mapa 1990/1995.

De esta forma, se puede afirmar que por lo menos hasta ahora, las medidas tendientes a la Reforma Fiscal no produjeron estabilidad y más bien parecen haber acrecentado la desarticulación del sistema incrementando los usos políticos de los márgenes negociables entre el Gobierno Central y las Provincias.

Como puede verse en el Cuadro № 5, el país en promedio supera con sus gastos totales el $30 \%$ de los recursos tributarios, pero son muy

\begin{tabular}{|c|c|c|c|c|c|c|c|c|c|}
\hline & & & Cua & $N$ & & & & & \\
\hline & & Emplec & $\begin{array}{l}\text { o públi } \\
1985\end{array}$ & /1993 & NOA & & & & \\
\hline Jurisdicciones & 1985 & 1986 & 1987 & 1988 & 1989 & 1990 & 1991 & 1992 & 1993 \\
\hline Tucumán & $\begin{array}{l}24,94 \% \\
37893\end{array}$ & $\begin{array}{l}23,98 \% \\
38163\end{array}$ & $\begin{array}{l}24,90 \% \\
45676 \\
\end{array}$ & $\begin{array}{l}24,63 \% \\
47326\end{array}$ & \begin{tabular}{|l|}
$23,96 \%$ \\
47548 \\
\end{tabular} & $\begin{array}{l}22,57 \% \\
44493 \\
\end{array}$ & $\begin{array}{l}21,93 \% \\
41411 \\
\end{array}$ & $\begin{array}{l}22,21 \% \\
42082\end{array}$ & $\begin{array}{l}22,55 \% \\
42344\end{array}$ \\
\hline Salta & $\begin{array}{l}19,20 \% \\
29,174 \\
\end{array}$ & $\begin{array}{l}21,26 \% \\
33822 \\
\end{array}$ & $\begin{array}{l}22,21 \% \\
40860\end{array}$ & $\begin{array}{l}23,04 \% \\
44273\end{array}$ & $\begin{array}{l}23,13 \% \\
45899 \\
\end{array}$ & $\begin{array}{l}22,44 \% \\
44224 \\
\end{array}$ & \begin{tabular}{|l|}
$22,66 \%$ \\
42802 \\
\end{tabular} & $\begin{array}{l}22,59 \% \\
42797 \\
\end{array}$ & $\begin{array}{l}22,14 \% \\
41567 \\
\end{array}$ \\
\hline Santiago del Estero & $\begin{array}{l}16,95 \% \\
25753 \\
\end{array}$ & $\begin{array}{l}15,34 \% \\
24402 \\
\end{array}$ & \begin{tabular}{|l}
$16,34 \%$ \\
29973 \\
\end{tabular} & $\begin{array}{l}15,88 \% \\
30528\end{array}$ & $\begin{array}{l}15,46 \% \\
30691 \\
\end{array}$ & $\begin{array}{l}16,50 \% \\
32525 \\
\end{array}$ & \begin{tabular}{|l|}
$16,40 \%$ \\
30973 \\
\end{tabular} & \begin{tabular}{|l}
$16,81 \%$ \\
31858 \\
\end{tabular} & $\begin{array}{l}16,84 \% \\
31612 \\
\end{array}$ \\
\hline Jujuy & $\begin{array}{l}14,72 \% \\
22358\end{array}$ & $\begin{array}{l}14,61 \% \\
23250\end{array}$ & $\begin{array}{l}14,38 \% \\
26366\end{array}$ & $\begin{array}{l}16,14 \% \\
31019\end{array}$ & \begin{tabular}{|l|}
$15,76 \%$ \\
31268 \\
\end{tabular} & $\begin{array}{l}15,86 \% \\
31268\end{array}$ & $\begin{array}{l}15,93 \% \\
30083\end{array}$ & $\begin{array}{l}15,21 \% \\
28816\end{array}$ & $\begin{array}{l}14,96 \% \\
28083\end{array}$ \\
\hline Catan & $\begin{array}{l}14,55 \% \\
22104\end{array}$ & $\begin{array}{l}14,26 \% \\
22695 \\
\end{array}$ & $\begin{array}{l}12,10 \% \\
22185 \\
\end{array}$ & $\begin{array}{l}11,20 \% \\
21517\end{array}$ & \begin{tabular}{|l|}
$11,40 \%$ \\
22615 \\
\end{tabular} & $\begin{array}{l}12,16 \% \\
23971 \\
\end{array}$ & $\begin{array}{l}11,90 \% \\
22480 \\
\end{array}$ & $\begin{array}{l}12,00 \% \\
22752 \\
\end{array}$ & $\begin{array}{l}12,39 \% \\
23257 \\
\end{array}$ \\
\hline La Rioja & $\begin{array}{l}9,63 \% \\
14,626\end{array}$ & $\begin{array}{l}10,55 \% \\
16783 \\
\end{array}$ & $\begin{array}{l}10,00 \% \\
18344\end{array}$ & $\begin{array}{l}9,11 \% \\
17511\end{array}$ & $\begin{array}{l}10,29 \% \\
20430\end{array}$ & $\begin{array}{l}10,45 \% \\
20613 \\
\end{array}$ & $\begin{array}{l}11,18 \% \\
21122\end{array}$ & $\begin{array}{l}11,18 \% \\
21178\end{array}$ & $\begin{array}{l}11,12 \% \\
20868\end{array}$ \\
\hline Total NOA & $\begin{array}{l}100 \% \\
151908 \\
\end{array}$ & \begin{tabular}{|c|}
$100 \%$ \\
159115 \\
\end{tabular} & $\begin{array}{c}100 \% \\
183404 \\
\end{array}$ & $\begin{array}{c}100 \% \\
192174 \\
\end{array}$ & $\begin{array}{c}100 \% \\
198451 \\
\end{array}$ & \begin{tabular}{|c|}
$100 \%$ \\
197094 \\
\end{tabular} & \begin{tabular}{|c|}
$100 \%$ \\
188871 \\
\end{tabular} & \begin{tabular}{|c|}
$100 \%$ \\
189483 \\
\end{tabular} & $\begin{array}{c}100 \% \\
187731 \\
\end{array}$ \\
\hline$\%$ del NOA & $2005 \%$ & $19,54 \%$ & $19,65 \%$ & $19,78 \%$ & $19,73 \%$ & $19,36 \%$ & $18,63 \%$ & $180,73 \%$ & $18,43 \%$ \\
\hline Total País & $\begin{array}{c}100 \% \\
1006066\end{array}$ & \begin{tabular}{|r|}
$100 \%$ \\
1018260 \\
\end{tabular} & \begin{tabular}{|r|}
$100 \%$ \\
1014038 \\
\end{tabular} & $\begin{array}{r}100 \% \\
1011422 \\
\end{array}$ & \begin{tabular}{|c|}
$100 \%$ \\
1018625 \\
\end{tabular} & $\begin{array}{r}100 \% \\
757734 \\
\end{array}$ & \begin{tabular}{|r|}
$100 \%$ \\
814172 \\
\end{tabular} & $\begin{array}{r}100 \% \\
933324 \\
\end{array}$ & $\begin{array}{r}100 \% \\
971089 \\
\end{array}$ \\
\hline
\end{tabular}

Fuente: Secretaría de asistencia para la Reforma Económica Provincial. Tomo II. Diciembre de 1995. 
pocas las provincias que superan con sus recursos propios, la posibilidad de cubrir el 20\% de sus erogaciones. A decir verdad solo lo logra con creces La Ciudad de Buenos Aires (86\%), y las Provincias de Buenos Aires, Córdoba, Santa Fé y Mendoza y del resto algunas alcanzan al 20\%, pero la gran mayoría no alcanza más que el 10 o el $12 \%$. Es el caso de las provincias patagónicas y más grave aún en las provincias del NOA que regionalmente no alcanzan más que a un $0.09 \%$ e individualmente sólo Tucumán y Salta alcanzan el $12 \%$ y $13 \%$, el resto tiene proporciones muy inferiores. (Ver Cuadro 3 )

Esto produce fuertes presiones entre los gobiernos provinciales y el gobierno central en disputa por los fondos provenientes del Régimen de Coparticipación y pone a los gobiernos provinciales en situaciones reiteradamente difíciles a la hora de dar cuenta frente a los ciudadanos sobre las políticas sociales.

Esto es lo que se llama desequilibrio fiscal vertical se acrecienta entre el primer y segundo mapa aumentando alrededor del 10\% las erogaciones de las provincias entre la primera fecha y la segunda.

La falta de correspondencia entre ingresos y gastos se acrecentó por varias razones, entre otras por la transferencia de recursos hacia las jurisdicciones provinciales sin estar acompañadas de recursos, esto crea tensiones por la distribución de los recursos coparticipados y aumenta las desigualdades regionales.

Las políticas de transferencia deben tener un criterio devolutivo. Si la transferencia está vinculada con diferencias en la capacidad recaudatoria de cada jurisdicción y la necesidad de igualar el consumo de bienes públicos por parte de las diferentes jurisdicciones, debiera establecerse sobre la base de «criterios redistributivos».

Las transferencias interjurisdiccionales pueden ser condicionadas: con un fin determinado con contraparte o sin contraparte; o no condicionadas: fondos de libre disponibilidad y el gobierno local decide las prioridades, éstas son particularmente de interés provincial.

La legislación fiscal en la Argentina, es relativamente tardía, recién 
en 1973 se aprueba el Régimen de Coparticipación Federal por medio de la Ley 20221 que tiene un sistema único de distribución de impuestos coparticipados y la determinación de coeficientes de reparto secundario, donde los criterios redistributivos tienen mucha importancia ${ }^{26}$.

Especialmente, porque la definición de estos coeficientes secundarios pueden calcularse de diferentes maneras, según los diferentes postulados políticos. De hecho, durante la década del '80, las relaciones financieras entre Nación y provincias son más conflictivas y se produce un proceso de desarticulación del régimen de coparticipación federal.

En 1987 se aprueba la Ley 23548 de Régimen Transitorio, que algunos autores caracterizan como altamente frágil. Durante esta década se dan dos tendencias simultáneas, por un lado, una creciente incorporación de tributos nacionales que se agregan al conjunto de recursos coparticipados y, por el otro, el aumento del coeficiente de distribución primaria.

La primera muestra el tránsito desde un régimen primitivo y fragmentado que involucra a solo tres de los tributos recaudados por la Nación, hasta la sanción de regímenes unificados que trataron de ordenar la distribución de la casi totalidad de los impuestos recaudados por la DGI.

La segunda, muestra la evolución en aumento de los coeficientes de distribución primaria, que en un principio no tenía coeficientes fijos.

En la nueva norma, la diferencia fundamental con la 20.221 era que los criterios se basaban en la distribución efectivamente realizada durante el período 1985/87, cuando no existía una norma que rigiera la coparticipación y el reparto se realizaban de acuerdo a las necesidades de cada jurisdicción el poder de negociación de los gobiernos y los legisladores de las diferentes jurisdicciones.

El resultado de este proceso fue la pérdida de importancia relativa

\footnotetext{
26 El Régimen de Coparticipación Federal tiene cuatro características: 1) solo se distribuyen los impuestos nacionales, no se incluyen los externos;2) se estipuló un mecanismo igual para la nación que para las provincias;3)se crea el Fondo de Desarrollo Regional, financiado con un 3\% de lo recaudado; 4) Los coeficientes de reparto secundarios estipulados por esa ley resultaron de la combinación de tres criterios: a) el 65\% de los recursos se reparten de acuerdo con la población de cada distrito; b) el 25\% en relación a la brecha de desarrollo entre las regiones; y c) el 10\% restante según la dispersión de la población .Cf. Cetrángolo y Jimenez, 1998.
} 
de la coparticipación de impuestos como instrumento de regulación de las relaciones financieras entre los diferentes niveles de gobierno y la multiplicación de mecanismos de transferencia de recursos, con lo cual se hace cada vez más difícil enfrentar las crisis provinciales.

Esto ha ido conformando un peculiar federalismo fiscal caracterizado por un sistema fragmentario de transferencias financieras entre diferentes niveles de jurisdicción.

La mayor conflictividad financiera entre la Nación y las provincias tiene tres causas: las circunstancias macroeconómicas, la crisis previsional y la conflictividad política.

Las circunstancias macroeconómicas generalmente muy inestables obligaron a la recurrencia de políticas de estabilización que tuvieron múltiples consecuencias sobre el tipo de cambio y la estructura productiva de cada región. Con ello se afectó la generación de recursos fiscales porque se redujo la base imponible y se alentaron demandas tendientes a reducir la presión impositiva local con el objeto de lograr mejoras en la rentabilidad empresaria utilizando instrumentos fiscales.

También se afectaron las negociaciones de la deuda pública y los cambios de precios relativos que inciden de manera diferente sobre los distintos rubros del gasto público y tienden a modificar la estructura jurisdiccional del gasto.

Otro factor que generó fuertes desequilibrios, fueron los destinados a atender las erogaciones del sistema previsional, que todos los gobiernos tuvieron que enfrentar de alguna manera.

La gran crisis del sistema previsional también gravitó sobre la distribución de impuestos entre la nación y las provincias. Estas presiones fueron crecientes a lo largo de los últimos años, hasta que como resultado de una reforma previsional con serias fallas en su diseño financiero, los gobiernos provinciales han debido resignar una importante porción de los recursos coparticipables para atender los gastos del sistema previsional.

Por otra parte, hay que agregar como variable de análisis la disputa 
política del período sin la cual no se logran comprender la reasignación de recursos por parte de las provincias y las firmas de pactos y acuerdos entre Nación y provincias. Todos estos factores fueron los que funcionaron como uno de los determinantes de la propensión a trabajar «en negro» como señalábamos al comienzo y tuvo fuertes reprecusiones en el aumento de las desigualdades regionales, como muestra el mapa.

De manera que hacer una corrección actual a este panorama no es fácil. La primera ley global de coparticipación sancionada en 1973 reconocía partes iguales a Nación y provincia. Los parches y componendas de la ley 23548 ha significado mayores fondos a la Nación que para las provincias en una proporción de $60 \%$ Nación y 40\% a las provincias, en 1996.Por ello es razonable pensar que en el futuro serán necesario cambios. Específicamente, con relación al sistema previsional, que se encuentra en transición y en el que todavía persisten restos del sistema anterior.

Según demuestra Cetrángolo (Cf. Cetrángolo, O., 1994 y también Rofman, R., 1998) el nuevo sistema tiene defectos de diseño similares al anterior y su transición promete ser mucho más larga de la que promete el gobierno.

Es más, el gobierno solicita la sanción de la denominada «Ley de solidaridad previsional» que instala un criterio de caja ante la posibilidad de hacer frente a las erogaciones que exige el sistema. ${ }^{27}$.

Según Porto (1990) la provincias avanzadas ( Buenos Aires, Santa Fé, Córdoba y Mendoza) decrecieron en su participación secundaria en un 18\% entre 1960 y 1988, mientras que en las rezagadas (La Rioja, Catamarca, Corrientes, Jujuy, Misiones, Chaco, Santiago del Estero, Formosa) crecieron en su participación en un $28 \%$ durante el mismo período.

Del desagregado de provincias se puede observar que hay provincias que reciben una mayor proporción de coparticipación federal que el resto. 


\begin{tabular}{|l|c|c|c|}
\hline \multicolumn{4}{|c|}{$\begin{array}{c}\text { Cuadro No6 } \\
\text { aportes patronales del NOA }\end{array}$} \\
\hline Jurisdicciones & $\begin{array}{c}\text { Aglomerados } \\
\text { urbanos }\end{array}$ & $\begin{array}{c}\text { Provincias excepto } \\
\text { aglom. Urbano }\end{array}$ & $\begin{array}{c}\text { Modificaciones al } \\
\text { 10 de abril de 1995 }\end{array}$ \\
\hline Catamarca & 60 & 65 & 30 \\
\hline La Rioja & 70 & 75 & 40 \\
\hline Jujuy & 60 & 65 & 30 \\
\hline Salta & 70 & 75 & 40 \\
\hline Santiago del Estero & 75 & $60 / 80$ & 45 \\
\hline Tucumán & 60 & 65 & 30 \\
\hline
\end{tabular}

En 1985, son Buenos Aires, Santa Fé y Córdoba que conjuntamente reciben el $37,12 \%$ del total, mientras que las provincias del NOA reciben el 22,01\%.

En 1991, estas mismas provincias reciben el 39,5\% de la transferencia a las provincias, mientras que las provincias del NOA reciben el 20,30 \%. La diferencia porcentual de la disminución es de 1,71\% para las provincias del NOA, mientras que para las «provincias ricas» es de 2,38\% más que en 1985.

Si tomamos los puntos extremos del período en que los valores son más altos- es decir en valores absolutos aumentan hasta 1993 los fondos de transferencia por coparticipación federal para todas las provincias, el porcentaje para las provincias del NOA es de 19,65\%, es decir, que en términos relativos bajó y las «provincias ricas» en 1993, reciben el 41,40\% de las transferencias, o sea que en términos relativos, también aumentó su participación. (Cf. Cuadro $\mathrm{N}^{\circ} 1$ )

El comportamiento para las provincias del NOA es bastante estable, también Santiago del Estero es la que tiene mayor caída al final del período y Jujuy la que se ve más favorecida por un leve aumento.

Los prorrateadores utilizados para la distribución secundaria también variaron, por ejemplo, para la aplicación de la ley 23548, fue el índice de NBI (Necesidades Básicas Insatisfechas) del INDEC, que no se había utilizado en casos anteriores, con lo cual se premia positivamente la pobreza y 
no se estimulan las conductas hacia la disminución de la evasión fiscal.

En este sentido, consideramos de mucho mayor utilidad un mapa de propensión al trabajo sin aportes para establecer los prorrateadores porque son específicos para este tema y sancionan positivamente a las provincias donde tiende a disminuir el trabajo en negro.

Hay distintos tipos de transferencias de fondos. Las transferencias condicionadas sin contraparte son recomendadas para subsidiar actividades de alta prioridad para el gobierno central y baja prioridad para el gobierno local, en especial, cuando el objetivo es de asegurar un nivel básico y uniforme de provisión para un determinado servicio.

La determinación del nivel de transferencia para cada jurisdicción remite a una discusión todavía no saldada sobre si la equidad que se busca sostener es entre regiones o entre individuos; si lo que se quiere es administrar la pobreza o incentivar la inversión y la no evasión de impuestos.

La otra variable que complementa el comportamiento de las provincias respecto de la recepción de fondos coparticipables y la reforma previsional es el tamaño del empleo público. Lo que suele suceder es que a mayor recepción de recursos tiende a aumentar el tamaño del empleo estatal.

No obstante, el empleo público no siguió este patrón- a nivel paíssino que creció cuando las transferencias tendieron a ser estables y luego creció menos cuando las transferencias crecieron.

Es bastante particular el comportamiento de las provincias del NOA con el empleo público. Salta y la Rioja aumentan su empleo público en 2,94\% la primera y en 1,49\% la segunda. Sin embargo en 1989 alcanza Salta una diferencia del comienzo del período de 3,93\% y La Rioja, alcanza en 1991 su mayor diferencia con 1,55\%.

Las provincias del NOA que menos recursos de coparticipación reciben, en términos absolutos, tienen la mayor cantidad de empleados públicos cada 1000 habitantes. Es el caso de La Rioja que tiene más de cuatro veces que la cantidad de empleo público cada 1000 habitantes que 
tiene Buenos Aires en 1989 y Catamarca que tiene casi 6 veces la cantidad de empleo público cada 1000 habitantes que tiene Buenos Aires en 1985.

Esto hace suponer que estaría contenido el desempleo con empleo público, porque los niveles de subempleo son ya muy altos y los lugares de inserción informal de empleo están muy saturados y no hay otras actividades que demanden mano de obra.

Las provincias del NOA ratifican sus convenios de adhesión al Pacto Federal por el Decreto 14/94 y 378/94, pero como consecuencia de la crisis fiscal, a principios de 1995, el Gobierno Nacional dispuso modificar nuevamente las alícuotas a la contribución patronal a través del Decreto $372 / 95$, que rige desde el 1 de abril y que contempla un incremento del $30 \%$, en los aportes patronales de la industria, el agro y el turismo y la investigación científica y el 30\% de rebaja para el comercio y los servicios. Finalmente, el Decreto 292/95 establece regresar a las alícuotas establecidas por el Decreto 2609/93 que se mantuvo vigente hasta la implantación del Decreto 872/95.

Para el NOA se producen los mayores descuentos de los aportes patronales, del orden del $75 \%$ y esto impacta en todas las actividades, pero como se señaló más arriba, particularmente en la minería porque son zonas de bajo desarrollo.

La disminución de los aportes patronales, no produce un aumento del empleo, pero se mantiene alto el empleo estatal a través de planes estatales de empleo como «Trabajar»y «Joven» donde se pagan remuneraciones sin aportes y cercanos a los valores mínimos. Es decir, se reduce la calidad de los empleos en el Estado, a costa de mantener lugares de inserción alternativos para la crisis productiva, dado que el aumentar los ingresos de coparticipación lo que puede crecer es el empleo en el Estado.

El sector productivo privado no resulta suficientemente dinámico como para absorber los trabajadores expulsados de las empresas estatales privatizadas, aunque el dinamismo de las exportaciones de la región asegura una demanda de mano de obra creciente, si se estabilizan estos niveles de 
comercialización.

La región del NOA en exportaciones regionales es la tercera en importancia con un crecimiento de un $7 \%$ en el período. En el NOA, la provincia de Jujuy incrementa sus colocaciones en el exterior en un $22 \%$ con el carbón vegetal y los minerales de plomo. Las exportaciones de manufacturas de origen agropecuario aumentan solo el 3\% en el conjunto del NOA y la más dinámica dentro de este rubro es Tucumán con el 8\% de crecimiento de la exportación de alcohol de caña.

En cuanto a las exportaciones de manufacturas de origen industrial el NOA está entre las regiones que disminuyen sus exportaciones de este tipo. En cambio, el NOA resulta la región más dinámica en la exportación de combustibles y energía con un crecimiento del 35\%.

Dentro del NOA, la provincia de mayor crecimiento es Salta con una tasa cercana al $36 \%$ de las exportaciones y también alcanzan valores significativos Santiago del Estero y Tucumán.

7. Comentarios finales sobre la crisis de empleo de origen fiscal

La reestructuración productiva y la crisis fiscal afectan especialmente a aquellas provincias que se gestionaban con un modelo de desarrollo con importante presencia estatal, sostenida por fuertes aportes del Gobierno Central y en el marco de una economía de poca diversificación.

La reestructuración de la participación del Estado en la economía y la ley de convertibilidad agregan a partir de 1991 nuevos equilibrios en las relaciones entre el Estado, los gobiernos provinciales y los gobiernos municipales y significa el fin del financiamiento de origen inflacionario del sector público.

Los dos primeros Pactos Fiscales aseguraron la desregulación de la economía y una suerte de unificación del régimen impositivo que era muy necesaria. Como marcamos más arriba el sistema logra ser superavitario por 
esta vía hasta $1994^{28}$.

La construcción de los dos mapas de Economía Subterránea (1980/ 85 y 1990/95) nos permite afirmar que el origen de las crisis provinciales del empleo tienen causales diferentes según se trate de desajustes fiscales o productivos y se agrava considerablemente cuando se suman ambos. No obstante, se mantiene cierta estabilidad de demanda en aquellas provincias dotadas de infraestructura importante.

Las necesidades crecientes de financiamiento de las provincias en el segundo período fueron paliadas, en muchos casos con el crecimiento de la deuda flotante, producida por la postergación de los compromisos salariales y previsionales, y el mantenimiento de un elevado empleo público, que derivó muchas veces en críticos estallidos provinciales.

También se agregan a los problemas de orden fiscal, los derivados de la ineficiencia de la gestión (corrupción, mala administración, utilización de clientelismo político, mala asignación de recursos propios o poca presión política para conseguir fondos del Gobierno Central, etc.)

Otra forma de crisis financiera que afectó a las provincias patagónicas tiene su origen en las políticas de exportación y cambiarias que sufrieron los efectos de la crisis mexicana, luego de la asiática y por último de la brasileña.

Mientras que en los sectores privados la creación de empleo es de carácter precario, preferentemente en construcción, comercio o servicios personales. Cuando en los sectores más informales de la economía disminuyen los lugares de inserción, lo que aumenta es la desocupación abierta o el empleo pagado en negro o sin aportes. En los sectores estatales se mantienen los niveles de empleo, pero aumenta el trabajo sin aportes, modalidades promovidas o a prueba acompañados a una tendencia creciente a la baja de los montos salariales

\section{Anexo}

Los métodos de análisis de clusters clasifican los casos o elementos 
en grupos sobre la base de criterios cuantitativos o cualitativos (distancias o similaridades).Genéricamente se denomina «proximidad» al conjunto de medidas que indican si dos o más elementos son cercanos o lejanos, empleando para su cálculo una o más variables. En este caso se trabajó con una matriz de datos euclídea, que se calcula empleando la siguiente expresión:

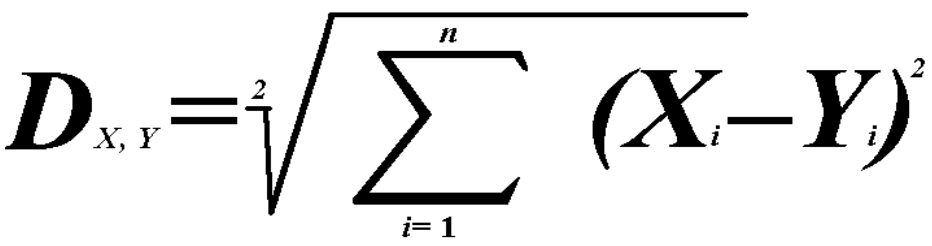

donde xi e yi representan las coordenadas de los vectores x e y. Hay dos grandes categorías de análisis de clusters:

- las que emplean métodos jerárquicos.

- las que emplean métodos no jerárquicos.

Los métodos jerárquicos forman los grupos en pasos sucesivos y pueden analizar en cada caso las distincias entre los grupos formados. Los métodos no jerárquicos realizan una sola partición de los casos iniciales en $\mathrm{M}$ agrupamientos. Este número $\mathrm{M}$ se determina a priori. En general, los métodos jerárquicos son más rápidos que los no jerárquicos, pero pueden conducir a clusters menos claros y peor definidos.

\section{Referências bibliográficas}

AXELRAD, Silvina. El impacto de la reestructuración económica sobre el mercado de trabajo neuquino. Estudios del Trabajo, Buenos Aires, n.15, 10 semestre de 1998.

ALASINO, Carlos M. Mercado de trabajo femenino, empleo público en las 
Sociologias, Porto Alegre, ano 2, no 4, jul/dez 2000, p.306-351

provincias y crisis fiscal. Estudios del Trabajo, Buenos Aires, n. 12 , 2o semestre de 1996.

ALVAREZ Cáceres, R. Estadística multivariante y no paramétrica con SpSS; aplicación a las Ciencias de la Salud. Madrid, Ediciones Díaz Santos, 1995.

ANDERSON, T.W. An introduction to multivariate statistical analysis. Nueva York, John Wiley \& Son Inc.; Londres, Sydney, 1958.

BARTHELEMY, Ph. La naturaleza de la economía subterránea en Francia en Economía No registrada. Estudios INDEC-BCRA-OEA, Buenos Aires, n.9, 1987. BARBEITO, Alberto. La integración de los sistemas de transferencias fiscales como instrumento de integración social. In: LO VUOLO, R. (Comp.). Contra la exclusión. La propuesta del ingreso ciudadano. Buenos Aires, CIEPP/Miño y Dávila, 1995. BECCARIA, Luis; ORSATTI, Alvaro. Precarización laboral y estructura productiva en la Argentina 1974-1988. In: GALÍN, P.; NOVICK, M. (Comp.). La precarización del empleo en la Argentina. Buenos Aires, CEAL-CLACSO-CIAT/OIT, 1990. BECCARIA, Luis; CARCIOFI, Ricardo. Políticas públicas en la provisión y financiamiento de los servicios sociales. Aportes para una agenda de los años 90. In: MINUJíN, Alberto (Ed.). Desigualdad y exclusión. Buenos Aires, UNICEF/ LOSADA, 1993.

BECCARIA, Luis. Estancamiento y distribución del ingreso. In: MINUJíN, Alberto (Ed.). Desigualdad y exclusión. Buenos Aires, UNICEF/LOSADA, 1993.

BECCARIA, Luis; LÓPEZ, N. (Comp.). Sin trabajo. Buenos Aires, UNICEF/LOSADA, 1996.

BENKO, George; LIPIETZ, Alain. Las regiones que ganan. Valencia, Ed. Lorenzo el Magnánimo, 1995.

BISQUERRA, R. Análisis mulrivariable. Barcelona, Ed. PPU, 1989.

BRAMBILLA, Irene; PORTO, Guido; POSADAS, Josefina. Desarrollo, crecimiento regional y política económica. Causas y efectos de la concentración de la actividad económica. La Plata, MEPBA, 1998.

CETRÁNGOLO, Oscar; JIMÉNEZ, Juan Pablo (Colaboración de Daniel Vega). Algunas reflexiones sobre el federalismo fiscal en la Argentina. Apuntes para el diseño de un nuevo sistema de coparticipación federal de impuestos. Desarrollo Económico, Buenos Aires, v.38, Número Especial, Otoño de 1998.

CHARMES, Jacques. El sector informal en las grandes encuestas estadísticas y la 
contabilidad nacional. Revisión y lecciones extraídas de algunas experiencias en «Economía no registrada». Estudios INDEC-BCRA-OEA, Buenos Aires, n.9, julio, 1987.

CHARMES, Jacques. El sector informal. Buenos Aires, Ed. Humanitas, 1992. CEB. Informe de Conyuntura. La problemática del empleo en la Argentina de los '90. CEB, v.7, n.69, agosto/setiembre, 1997.

CONESA, Eduardo. Desempleo, precios relativos y crecimiento económico. Buenos Aires, Ediciones De palma, 1996.

DE GRAZIA, Rafaelle. Le travail clandestin. Gèneve, OIT, 1983.

DIEGUEZ, Llach y Petrecolla. El gasto público social. Buenos Aires, ITDT Programa conjunto Gobierno Argentino/Banco Mundial/PNUD, 1990.

DURÁN, Viviana; GÓMEZ Sabaini, J. C. Lecciones sobre reformas fiscales en Argentina. Santiago de Chile, CEPAL, 1995. (Serie Política Fiscal n.68) DURÁN, Viviana. Estructura y rendimiento de los sistemas tributarios de Argentina y algunos países relacionados. Buenos Aires, CITAF T.36. OEA, 1996.

FELDMAN, Silvio. Contratos laborales promovidos: su uso en el sector privado. Estudios del Trabajo, Buenos Aires, n.8/9, Primer Semestre, 1995.

fiel. El gasto público en la Argentina 1960/88. Buenos Aires, 1990. Subsecretaría de Relaciones Fiscales con las provincias «Situación de las provincias argentinas», dic, 1994.

FREY, Bruno; WECK, H. What Produces a Hidden Economy? An International Cross Section Analysis. Southern Economic Journal, North Carolina, v.49, n.3, enero, $1983^{\mathrm{a}}$

FREY, Bruno; WECK, H. Estimating The shadow Economy: a "naive approach". Oxford Economic papers, v.35, n.1, marzo, 1983 b.

FREY, Bruno; WECK, H. The Hidden Economy as an unobserved variable. European Economic Review, v.26, n.1/2, oct/nov. 1984.

FRIEDMANN, John. Futuros de la ciudad global. El rol de las políticas urbanas y regionales en la región Asia-Pacífico. Eure, Santiago de Chile, v.23, n.70, diciembre, [1997].

GÓMEZ SABAINI, Juan C.; GAGGERO, Jorge. Lineamientos para una reforma del sistema tributario argentino. La Plata, MEPBA, 1997.

GONZÁLEZ López-Valcárcel, R. Análisis multivariante, aplicación al ámbito sanitario. Barcelona, SG. Editores, 1991. 
Sociologias, Porto Alegre, ano 2, no 4, jul/dez 2000, p.306-351

GUISARRI, Adrián. La demanda de circulante y la informalidad en la Argentina 1930-1983. Buenos Aires, s/ed, 1987. (mimeo)

JÖRESKOG, R. G.; GOLDERBERGER, A. S. Estimation of model with multiple indicators and multiple cuases of a single latent variables. Journal of the American Statistical Association, n.70, set. 1975.

JÖRKESKOG, R.G.; VAN THILLO. A general computer program for lineal structural equation system involving multiple indicators of unobserved variables. LISREL, Uppsala, Departament of Statistics University Of Uppsala, p.73-75, 1973.

KATZ, Jorge (Ed.). Estabilización macroeconómica, reforma estructural y comportamiento industrial. Santiago de Chile, CEPAL/IDRC/Alianza Editorial, 1996.

LAMARCHE,Carlos; PORTO, Guido. Efectos de medidas de política económica sobre el empleo regional. La Plata, MEPBA, 1997.

LIPITEZ, Alain. La société en sablier. Paris, La Découverte/Poche Essais, 1998.

LÓPEZ, Néstor; MONZA, Alfredo. Un intento de estimación del sector informal urbano en la Argentina. Desarrollo Económico, Buenos Aires, v.35, n.139, oct/ dic. 1995.

LO VUOLO, Ruben. Reformas previsionales en América Latina: una visión crítica sobre la base del caso argentino. Estudios del Trabajo, Buenos Aires, n.11, 1er Semestre, 1996.

LUDUEÑA, Ignacio. El papel del Ferrocarril Gral Belgrano. Seminário regional de Economia y Empelo en el Noroeste Argentino. Salta, MTSS, 1994

MARSHALL, Adriana; ORLANSKY, Dora. Inmigración de países limítrofes y demanda de mano de obra en la Argentina, 1940/1980. Desarrollo Económico, Buenos Aires, v.23, n.89, abril/junio, 1983.

MARSHALL, Adriana. El empleo público frente a la crisis: estudios sobre América Latina. Ginebra, IIEL, 1990.

MEyOSP. Informe Económico Regional. Diciembre, 1996.

MTySS (Sistema Integrado de Inspección del Trabajo y de la Seguridad Social). Informe. Noviembre, 1997.

MINUJíN, Alberto (Ed.). Desigualdad y exclusión. Buenos Aires, UNICEF/LOSADA, 1993.

MONZA, Alfredo. El empleo al interior del sector terciario. Seminario sobre terciarización del empleo en la Economía Argentina 1947/1980. Buenos Aires, 
MTSS/Secretaría de Planificación, 1985.

MURMIS, Miguel; FELDMAN, Silvio. De seguir asi. In: BECCARIA, Luis; LÓPEZ, N. (Comp.). Sin trabajo. Buenos Aires, UNICEF/LOSADA, 1996.

NEIMAN, Guillermo. Transformaciones agrarias y mercados de trabajo, regiones procesos y sujetos. Dialógica, v.1, n.1, 1996.

OIT. La medición estadística del empleo en el sector no estructurado. Ginebra, Informe n.1 OIT, 1992.

OTRERA, Wylian. Emprendimentos viales. La salida al Pacífico. Corredores de transporte para productos exportables. Telecomunicaciones. Seminário regional de Economia y Empelo en el Noroeste Argentino. Salta, MTSS, 1994

PANAIA, Marta. Indicadores sociales. Evaluación de instrumentos metodológicos para explicar los procesos sociales en crisis. Buenos Aires, OEA, 1988. (mimeo) PANAIA, Marta. Crisis y trabajo precario en la industria de la construcción. In: GALÍN, P.; NOVICK, M. (Comp.). La precarización del empleo en la Argentina. Buenos Aires, CEAL-CLACSO-CIAT/OIT, 1990.

PANAIA, Marta. El trabajo negro en la Argentina. Cuaderno Instituto de Investigaciones de la Facultad de Ciencias Sociales, Buenos Aires, n.4, noviembre, 1991.

PORTO, A. Federalismo fiscal. El caso argentino. Buenos Aires, Instituto Di TellaEditorial Tesis, 1990.

RAGZINSKI, Dagmar. El sector informal urbano: controversias e interrogantes. Cieplan, n.13, julio, 1977.

ROFMAN, Rafael. El sistema previsional argentino a cuatro años de la reforma: los temas pendientes. Ponencia presentada al 4to Congreso Nacional de Estudios del Trabajo ASET, 4 al 6 de noviembre de 1998.

SABA, Andrea. La industria subterránea. Un nuevo modelo de desarrollo. Valencia, Ed. Lorenzo El Magnánimo, 1981.

SABA, Andrea. El modelo italiano. La especialización flexible y los distritos industriales. La Plata, Editorial de la Universidad de La Plata, noviembre, 1997.

SALVIA, Agustín; DONZA, Eduardo; PHILIPP, E. Cambio estructural y distribución del ingreso 1980/1996. DT Instituto de Investigaciones Gino Germani, Facultad de Ciencias Sociales/UBA, Buenos Aires, n.6, 1998.

SALVIA, Agustín; PANAIA, Marta (Comp.). La Patagonia privatizada. Buenos Aires, Ediciones CEA/CBC/PAITE, 1997. 
SALVIA, Agustín (Comp.). La patagonia de los '90.Sectores que ganan, sociedades que pierden. Buenos Aires, Ed. La Colmena/UNPA/UBA, 1999.

SANCHIS, E. La otra economía. Trabajo negro y sector informal. España, Ed. Alfonso El Magnánimo, 1988.

SANTIERRE. Distribución de la carga tributaria por niveles de ingreso. Gobierno Argentino/Banco Mundial, 1989.

SASSEN, Saskia. The Global City: New York, London, Tokyo. Princeton, NJ, Princeton University Press, 1991.

SASSEN, Saskia. Cities in the World Economy. Thousand Oaks, CA, Pine Forge Press, 1994.

SHIRAY, Michel. L'economie cachée. París, CNRS, 1983/1.

SCOTT, Allen J. Regional Motors of the Global Economy. Futures, Michigan, v.28, n.5, 1996.

TOKMAN, Victor. Una exploración sobre la naturaleza de las interrelaciones entre los sectores formal e informal. In: TOKMAN, Victor; KLEIM, Emilio (Comp.). El subempleo en América Latina. El Cid. Editor/CLACSO, 1979.

ZURITA, Carlos. El mercado de trabajo en un escenario regional. Acotaciones sobre el noroeste argentino. Digitado sem publicar, 1999. 


\section{Resumen}

El trabajo se enmarca dentro de los estudios de génesis, crecimiento y dinamismo del sector informal y aumento o disminución de la propensión a trabajar en condiciones de informalidad, ya sea por la forma de contrato (precariedad); por la falta de pago (evasión previsional o comunmente llamado «en gris» o « en negro» por su característica de clandestinidad (ilegalidad) o por realizarse en unidades económicas informales.

En el contexto económico de la década del '90, en la Argentina, con las nuevas medidas que construyen un nuevo perfil del mercado de trabajo, se analizan los determinantes del mercado de trabajo sin aportes utilizando los datos de la construcción de un mapa de propensión al trabajo en negro, en base a un método de análisis de inobservables de fenómenos de multiples causas y múltiples consecuencias.

El mapa construido para todo el país, en una investigación anterior, sirve de base para un análisis más profundo de la zona del Noroeste Argentino, una de las regiones más desfavorecidas del país y donde la propensión al aumento del trabajo en negro es más intensa, contrastándolo con los del total del país.

Palabras clave: desempleo, informal, sin aportes,crisis fiscal. 